CAPÍTULO 4

\title{
ESTRATEGIAS DE ADMINISTRACIÓN DE LAS PEQUEÑAS UNIDADES PRODUCTIVAS DEL ESTUDIO
}

\author{
Hernán Guillermo Saumett-España ${ }^{1}$, Hilda Helena Estrada-López²,
} Adriana Marcela Cáceres-Martelo ${ }^{3}$

1 Sociólogo, Universidad Simón Bolívar. Magíster en Proyectos de desarrollo social, Universidad del Norte. Docente-Investigador del Grupo Innovación y Desarrollo Empresarial-GIDE. Universidad Simón Bolívar, Barranquilla (Colombia).

herse47t@unisimonbolivar.edu.co

2 Administradora de Empresas, Universidad Autónoma del Caribe. Doctor en Administración de Empresas, Universidad Autónoma de Querétaro, México. Investigadora del Grupo Innovación y Desarrolo Empresarial-GIDE. Universidad Simón Bolívar, Barranquilla (Colombia). Docente en la Facultad de Ciencias Económicas de la Universidad del Atlántico, Barranquilla (Colombia). hileslo@hotmail.co

3 Contadora Pública, Universidad Simón Bolívar, Barranquilla (Colombia). acaceres4@unisimonbolivar.edu.co 


\section{RESUMEN}

En este capítulo se presentan las estrategias utilizadas por los propietarios de pequeñas unidades productivas de frutas con las nuevas líneas de confitería nutracéutica. Los resultados forman parte del proyecto seleccionado por Colciencias en la convocatoria 713/2015 "Desarrollo de productos de confitería y fertilizantes para la generación de valor agregado asociado a la producción de productos agrícolas en el departamento del Atlántico", realizado en la zona rural del municipio de Santa Lucía, y las veredas ubicadas en el Municipio de Malambo. Se estudiaron las estrategias empleadas por cultivadores de frutas del departamento del Atlántico, tomando la información sobre la forma de administrar las unidades productivas, mediante entrevistas a los propietarios asociados a la Cooperativa Productora y Comercializadora de Productos Agrícolas del Sur del Atlántico, Cooagrosur, y la Asociación de Fruticultores de Malambo, Asofruma. Como resultado, se pueden captar los beneficios de las nuevas líneas de confitería nutracéutica y el uso de excedentes de las cosechas que se perdían por los procesos de maduración y ahora son utilizados para mejorar las condiciones del suelo como biofertilizantes.

Palabras clave: Nutracéutico, confitería saludable, biofertilizantes, procesos organizacionales.

\section{ABSTRACT}

This chapter presents the strategies used by the owners of small fruit production units with new lines of confectionery nutraceutical. The results are part of the project selected by Colciencias call 713/2015 "Development of confectionery products and fertilizers for the generation of added value associated with the production 
of agricultural products in the Department of the Atlantic", carried out in the rural area of the municipality of Santa Lucia, and located in the municipality of Malambo sidewalks. We studied the strategies employed by growers of fruits of the department of the Atlantic taking the information on how to manage the productive units, through interviews with owners associated with cooperative producer and trading company of agricultural products of the South of the Atlantic, COOAGROSUR, and the fruit growers Association of Malambo, ASOFRUMA. As a result can capture the benefits of new confectionery lines nutraceutical and surplus crops, which were lost by the processes of maturation and are used to improve the conditions of the land as fertilizers.

Key words: Nutraceutical, healthy confectionery, biofertilizers, organizational processes.

\section{INTRODUCCIÓN}

El propósito de esta investigación fue la de contribuir a la solución de las necesidades tecnológicas de productores agropecuarios del departamento del Atlántico mediante el desarrollo de tecnologías relacionadas con la formulación, evaluación y validación de tres líneas de confitería nutracéutica y una de biofertilizantes. Estas líneas de productos se elaboran a partir de frutales (mango, guayaba, limón) y hortalizas como el ají, cebollín y ahuyama; productos que responden a las necesidades de las cadenas de producción del sector agropecuario, priorizados en el Plan Nacional de Desarrollo 2014-2018 e incluidas en la agenda de I+D+i (PND, 2015). Se trata de agregar valor a productos del sector agropecuario que no realizan transformaciones, aun cuando tienen mercados para consumir ese producto con el nuevo valor agregado 
por un proceso de producción. Es una nueva opción de alimentos nutracéuticos en la categoría de confitería, que se comercializa de forma directa en tiendas especializadas y bajo la modalidad de licenciamiento.

El área de influencia del proyecto comprende el departamento del Atlántico en el Municipio de Santa Lucía, la zona rural de las veredas San Barreto, La Isla, La Esmeralda y el Bonguito, y las veredas El Tamarindo, Malambito, Monte Cristo, Loma Grande, y Caracolí, ubicadas en el municipio de Malambo. En esta zona se encuentran las fincas de cada unidad de los pequeños productores beneficiarios del proyecto, todos asociados a la Cooperativa Productora y Comercializadora de Productos Agrícolas del Sur del Atlántico, COOAGROSUR, y la Asociación de Fruticultores de Malambo, ASOFRUMA, respectivamente. Son productos que forman parte de la cadena de alimentos perecederos, los cuales, mediante el proyecto, mejoran su encadenamiento, aprovechando al máximo las ventajas comparativas de cada eslabón y su inserción actual en el mercado.

Los resultados de la investigación señalan formas que pueden mejorar la utilización de frutas y verduras que se pierden en tiempos de cosechas, y crea una nueva opción de negocio vinculada a la producción de alimentos saludables, los cuales han venido ganando presencia en el mercado por sus ventajas derivadas de ser productos naturales que les agregan componentes nutricionales a complementos alimenticios, considerados como confiterías y otros que se consumen fuera de las comidas.

En este capítulo se hace una revisión sobre los artículos y documentos relacionados con los alimentos funcionales y nutracéuticos, 
que cada día adquieren importancia en los patrones de consumo y generan un mercado en crecimiento, que hace sostenible negocios en este campo. También se tiene en cuenta la incidencia sobre el sector agropecuario para la economía de países en desarrollo como el nuestro. De tal manera que se hace énfasis en los planteamientos de un gremio como la ANDI, que analiza con preocupación los cambios en las inversiones y hace un balance sobre las perspectivas de Colombia para el año 2016, señalando factores que pueden afectar la economía del país. Esto se complementa con los estudios sobre las tendencias de los mercados de gran consumo, y la evaluación del plan de desarrollo del sector agropecuario que había trazado Colciencias.

La información anterior crea un marco de referencia para analizar las estrategias empleadas en pequeñas unidades productivas, mediante el aprovechamiento de tres líneas de confitería nutracéutica y una línea de biofertilizantes que le agregan nutrientes a los suelos con microorganismos, para recuperar la fertilidad, y garantizan la trazabilidad de alimentos de tipo orgánico sin utilizar productos químicos que dejan residuos contaminantes. De esta manera se pueden captar los procesos y estrategias administrativas utilizadas por los propietarios de estas unidades productivas, con el manejo de nuevos negocios y el aprovechamiento de los productos agrícolas que son transformados, con mayor valor agregado y de alto contenido nutricional.

\section{METODOLOGÍA}

Para la metodología se tuvo en cuenta lo que se presentó en el proyecto de Colciencias, relacionada con la segunda fase. Se trata del estudio de los productores vinculados a dos organizaciones, que le 
ofrecen asesoría para el desarrollo de las nuevas líneas de confitería nutracéutica y buscan impulsar el desarrollo empresarial como pequeños productores agrícolas. Esta fase se inicia con la revisión del estado del arte, en lo referente a publicaciones sobre evaluación del interés por los alimentos funcionales y nutracéuticos, con posibilidades de crear nuevas líneas que fortalezcan la economía de productores del campo colombiano. De manera que se obtienen referentes teóricos que enmarcarán la ruta más apropiada en el desarrollo de este trabajo.

La metodología empleada es de tipo cualitativo, basada en entrevistas y observaciones directas sobre el proceso y las estrategias utilizadas para administrar pequeñas unidades de productores agrícolas. El método utilizado toma elementos directamente de los pequeños productores agrícolas para describir la forma que asumen los procesos en estas unidades productivas, tal como lo señala Méndez (2005, p.135).

Se toma de la metodología cualitativa la técnica de entrevista en profundidad, con el ánimo de analizar en un ambiente propicio las percepciones de los pequeños productores agrícolas sin que haya otras influencias. La técnica hace que el moderador aliente al entrevistado para que exprese con entera libertad sus ideas sobre el tema de estudio y, en ciertos casos, se convierte en una ventaja sobre la sesión de grupo, pues la persona puede expresar inquietudes que no manifestaría en público. Se eligió metodología cualitativa porque se pretende conocer aspectos psicológicos de la forma como realizan la administración de sus fincas.

Con el uso de la entrevista se reconstruyen los elementos que conforman los perfiles socioeconómicos de cada unidad de estudio 
y de su propietario, ubicados en área rural de los municipios de Santa Lucía y Malambo del departamento del Atlántico. Se obtuvo información importante para conocer la forma en que ellos han aplicado, en sus unidades productivas, conceptos de administración; aquí se puede captar cuál es la capacidad con que cuentan, cómo gestionan la calidad de sus productos, los aspectos más significativos para la marcha del negocio, y la estrategia que emplean para garantizar el crecimiento del negocio y la manera de verificar los resultados obtenidos. Estas técnicas y métodos de corte cualitativo son combinadas, tal como lo indican Marais (2012), Denzin (2001) y Lee y Chang (2008), para obtener información cuantificable sin perder la comprensión del objeto estudiado.

Para el análisis de la información se utilizaron cuadros comparativos (matrices de doble entrada) con los resultados de la entrevista realizada, manteniendo en lo posible la forma como respondieron a las preguntas derivadas de los objetivos de esta investigación y relacionadas con las estrategias de administración utilizadas, tal como el propietario las concibe y la forma como la emplea, que es indiscutible, no corresponde exactamente a lo planteado en la academia y en los libros de administración.

\section{ESTADO DEL ARTE}

\section{El interés por los alimentos funcionales}

El interés por los alimentos funcionales tiene mucho que ver con el sobrepeso y la obesidad, considerados por Esperanza Torrija Isasa (2016) como uno de los principales problemas que afronta la sociedad actual. Esto se debe, de acuerdo a su investigación, a los cambios que han venido dándose en los estilos de vida y los alimentos que las personas consumen de manera constante. A 
pesar de los avances de la ciencia, sostiene la autora referenciada, todavía no se dispone de estudios confiables sobre la manera de disminuir peso consumiendo productos de uso diario.

Las dietas, en los años 80, son reconocidas en Japón como la oferta de alimentos funcionales para combatir la obesidad y el sobrepeso. Esto se ha extendido por todo el planeta como ayuda para obtener un peso y una talla adecuada, de manera que la sociedad tiende a buscar cambios en los alimentos, con efectos en otros comportamientos que llevan a mejorar la salud en los tiempos que se emplean para trabajar, y el tipo de alimento recomendado mediante dietas que mejoran las condiciones de vida. Por tal razón, la tecnología empleada en la preparación y la oferta de alimentos de toda variedad, son acompañados de una publicidad que hace al consumidor una persona enterada sobre los nutrientes y la cantidad indicada para mantenerse sano.

Todo parece indicar que además de los cambios en el consumo y los factores culturales ligados a esta oferta, en los restaurantes de diferentes tipos y categorías, refresquerías, cafeterías, casinos y comedores populares, se encuentran los equilibrios necesarios entre la dieta de consumo diario, los ingresos de los consumidores, el tipo de trabajo realizado y los tiempos dedicados al descanso y vacaciones. Tales cambios hacen de la industria de los alimentos una opción para tener en cuenta en la economía de un país.

Angie Higuchi (2015) realizó un estudio de los consumidores de productos orgánicos y cómo se amplía su oferta en la ciudad de Lima, Perú. En este se destaca la forma de identificar a los consumidores de productos naturales, y en una gráfica muestra el aumento 
de las tiendas especializadas que se han creado en los últimos once años, en los cuales se observa un mayor nivel de vida de los peruanos. De acuerdo al estudio, existe una correlación entre el nivel de ingresos de las personas y el consumo de productos de esta naturaleza. Ella encuentra que las tiendas que tienen una mayor acogida se ubican en sectores reconocidos como centros de consumo de personas con ingresos medios y altos, los que también tienen un mayor nivel educativo y valoran la necesidad de controlar los nutrientes en su alimentación. Por tal razón recomienda que estas tiendas se ubiquen en los sitios de mayor poder adquisitivo. Ahora que sí se tienen en cuenta los planteamientos de Torrija (2016) en cuanto al uso de tecnologías para la preparación de alimentos y los avances en la publicidad es posible que sectores de menor poder adquisitivo puedan acceder a la oferta de estos alimentos.

A propósito de lo anterior, vale la pena tener en cuenta el estudio piloto realizado por Barrena, R., García, T. y López-Mosquera, N. (2016), donde se fijan los determinantes socioeconómicos y emocionales que están presentes en el consumo de nuevos alimentos. A pesar de los esfuerzos realizados por las empresas, sostienen ellos, el índice de fracaso de los nuevos productos se debe fundamentalmente a no tener en cuenta los deseos del consumidor. De ahí que para que un nuevo producto alimentario, tenga acogida en el mercado, debe realizar una identificación de su mercado potencial y segmentar su mercado real.

Este conocimiento sobre el comportamiento del mercado ante un nuevo producto está relacionado con factores como las condiciones socioeconómicas de los consumidores, pero existe la tendencia a buscar productos innovadores, y la publicidad le ha creado un 
campo amplio a la innovativeness, o tendencia innovadora del consumidor, como un factor positivo en la preferencia, y aún más, la aceptación de nuevos productos que están más relacionados con las emociones percibidas en el momento del consumo.

Como se puede observar, es necesario analizar en qué medida el carácter innovador determina el consumo de nuevos alimentos, así como los efectos que tienen las emociones para darle al producto una mayor aceptación y ser preferidos ante productos similares. En el estudio también utilizaron modelos de ecuaciones estructurales para comprobar las relaciones causales, llegando a concluir que el nivel educativo y la percepción de emociones positivas influyen para bien en el carácter innovador de los consumidores.

La base de estos productos son las frutas, especialmente de las regiones tropicales que, además de su olor, sabor y color, tienen un atractivo adicional para los consumidores. Sobre este tema, Cárdenas, Arrazola y Villalba (2015) muestran los efectos de las "Frutas tropicales como fuente de compuestos bioactivos naturales en la industria de alimentos" (p.32). Ellos sostienen en su publicación que en los últimos años ha habido una tendencia global hacia el consumo de alimentos que proporcionen efectos beneficiosos para la salud.

La revisión que hacen sobre investigaciones les indica la importancia en el uso de compuestos bioactivos derivados de plantas como fuente de ingredientes funcionales en los productos alimenticios. Siguiendo esa orientación, sugieren que estos pueden disminuir el riesgo de enfermedades cardiovasculares y neurodegenerativas. Las investigaciones citadas se refieren a los componentes que 
tienen las frutas y aspectos de interés para conservar la salud, como son los componentes antioxidantes. Por lo tanto, esta revisión se centra en exponer el contenido de compuestos bioactivos presentes en frutas tropicales, evidenciando sus beneficios sobre la salud humana a través de su aprovechamiento agroindustrial en productos alimenticios, jugos con antioxidantes, en general fuentes bioactivas para la industria.

Tal como se ha venido planteando, el sector de la industria alimenticia es una perspectiva dentro de la cadena de valor. Hidalgo Nuchera (2009) se refiere a la experiencia que tiene Costa Rica en cultivos y procesamiento de productos agrícolas, sometidos a industrialización. Muestra cómo se comenzó a construir un conglomerado industrial para el procesamiento de alimentos, que ha ido adquiriendo una relevancia fundamental en la distribución de la riqueza, la generación de empleo y la calidad de vida de la población.

Hidalgo Nuchera (2009) encuentra que se trata de una industria donde la mayor parte de las empresas que la constituyen son de capital nacional y de tradición familiar, es decir, se iniciaron como micro, pequeñas y hoy son medianas empresas, lo cual demuestra que es un sector dinámico, con productos de calidad y con disposición a asumir retos. La actual coyuntura de la globalización, con la firma de tratados comerciales, crea la necesidad de desarrollar productos innovadores, saludables, funcionales y que respeten el medioambiente. Esto es indispensable en empresas grandes, pero representan retos y les abre una serie de oportunidades para pequeñas y medianas unidades productivas, que utilicen el ingenio y la innovación como fuente de competencia de sus productos. 
Dentro de la innovación y el ingenio está el análisis sensorial, mediante el cual es posible conocer las propiedades organolépticas de los alimentos. Esto lo afirma en su tesis de grado Mayra Alejandra Padilla (2013) cuando hace la evaluación del potencial nutritivo y nutracéutico de galletas elaboradas con berro. Sostiene que las personas hacen una evaluación sobre el producto alimenticio que prueban, indicando si les gusta o disgusta, y describen y reconocen sus características de sabor, olor y textura.

Por esa razón, la prueba y el análisis sensorial de los alimentos es un instrumento eficaz para su control de calidad y aceptabilidad. Esto es válido para comercializar, teniendo en cuenta que debe cumplir los requisitos mínimos de higiene, inocuidad y calidad del producto. Pero la prueba de aceptación garantiza las características que las personas buscan en determinadas marcas conocidas.

Padilla (2013) recomienda que se apliquen diversas pruebas para tener información confiable sobre las fuentes de contaminación del alimento, evaluar las normas de higiene utilizadas en la elaboración y manipulación. De esta manera es posible detectar la presencia de microorganismos que supongan un riesgo para la salud del consumidor. También explica que esto es necesario cuando se alteran o se agregan componentes con la finalidad de aumentar su período de conservación. Precisamente, uno de los objetivos más importantes de la Microbiología de alimentos es detectar la presencia de flora patógena para evitar riesgos en la salud del consumidor. Ella se refiere al examen microbiológico de alimentos como la investigación necesaria para identificar la presencia o ausencia de familias o grupos de microorganismos, cuya presencia refleja las condiciones higiénicas y sanitarias de estos productos, ya sean naturales, 
elaborados en la industria, o elaborados artesanalmente cuando se trate de comidas preparadas para ser consumidas inmediatamente.

Existe una preocupación sobre la calidad de los alimentos y los estilos de vida de la población, tal como lo señalan Patricia Arguedas, Mora y Sanabria (2015) al hacer la comparación del contenido de carotinoides en productos nutracéuticos elaborados a partir de dos variedades de camote y yuca dentro del proyecto de investigación Desarrollo de alimentos nutracéuticos a partir de cultivos biofortificados para combatir el efecto del cambio climático en la seguridad alimentaria de Costa Rica. Este fue un trabajo de investigación realizado en la Escuela de Ingeniería en Agro negocios, y con la participación de las escuelas de Química, Agronomía y Administración de Empresas. En el estudio hacen la identificación de las necesidades alimenticias de tres tipos de poblaciones: niños menores de dos años, adolescentes y adultos mayores.

En la elaboración de los productos utilizaron variedades de camote y de yuca biofortificados con carotenos. Para obtener diferencia nutricional entre un producto elaborado con las variedades biofortificados y uno elaborado con las variedades más comúnmente utilizadas por la población costarricense, compararon el consumo de un colado infantil y de snack para adolescentes, en donde se emplea el camote como ingrediente y en el snack tanto la yuca como el camote. Uno de los alimentos utiliza una yuca fortificada y otro no. Se pudo observar que usando las variedades biofortificadas se aumenta la asimilación de los carotenos.

De acuerdo a su estudio, el interés que existe en la sociedad por el valor nutritivo de los alimentos explica porqué Costa Rica y Chile 
son los países con mayor esperanza de vida en el continente. Costa Rica tiene un promedio de 80 años y Chile de 79 (Organización Panamericana de la Salud, 2014). Se trata entonces de una población enterada de los nutrientes que debe contener su dieta diaria, por cuanto la asocia a la salud y los estilos de vida saludables, tendencias que se notan en el interés de los productores de alimentos y de líderes de esta industria, para adicionar beneficios nutricionales a sus productos. Por eso sostienen que las universidades y las instituciones públicas, como los ministerios de Salud y de Agricultura, se constituyen en el motor para el logro de este objetivo.

Los latinoamericanos son consumidores de productos lácteos, su dieta alimenticia tiene componentes de estos productos y existe una gran variedad de presentaciones, sabores y texturas. Por esto en el Congreso Centroamericano del Sector Lácteo, la Cámara Nacional de Productores de Leche (2012), presentó una ponencia sobre las tendencias e innovaciones en el desarrollo de productos lácteos. En ella indican cuáles son las tendencias de los consumidores de estos productos y su preferencia por las formas de presentación.

En la ponencia se destaca que las personas encuestadas tienen preferencia hacia el placer que les proporciona el alimento, y este lo asocian a innovaciones, con una tendencia hacia "variedad de sentidos", en donde se juega con contraste de gustos y texturas ligeras. El orden de preferencia muestra los siguientes resultados:

1. La tendencia "sofisticación" disminuye, pero aun así es reconocida por los consumidores. Los productores afrontan la crisis tratando de buscar nuevas oportunidades para crecer, ofreciendo la gama de productos de descuento, y juegan con una oferta más valorizada y novedosa, especialmente en helados. 
2. El eje Salud sigue siendo importante con una progresión de la tendencia a "lo natural", representada por los productos orgánicos. Se nota un acercamiento con la tendencia "solidaridad", representada por productos "Bio u orgánicos y justos"; aquí se destacan los probióticos en los yogurts.

3. La Conveniencia se ilustra con la facilidad para "manipular el producto" que, aunque disminuye un poco, presenta innovaciones interesantes, como el queso para untar.

4. La variedad de los sentidos (eje de Placer) está ganando fuerza en América Latina, con innovaciones que involucran sabores "picantes" o sabores fuertes.

5. La innovación en el eje de Conveniencia está bajando, mientras que el eje de Salud se está afianzando, principalmente por medio de la disponibilidad de alimentos libres de grasas trans.

Hacen una presentación sobre los alimentos nutricionales que promueven la salud, entre los que destacan:

\section{Alimentos que ayudan a tratar ciertos desórdenes}

Productos elaborados con ingredientes adicionados o ingredientes presentes/ausentes naturalmente en los alimentos con beneficios para la salud que buscan llenar las expectativas del consumidor, como los productos sin lactosa y bajo en grasas.

El concepto de producto "vegetal" tranquiliza, gracias a que su composición natural se menciona con el propósito de dar seguridad sobre la inocuidad e integridad. Ellos le traen beneficios para la salud, provista por plantas o alimentos de origen vegetal (fibra, 
vitaminas), además el ingrediente vegetal se utiliza como una justificación para una clara promesa de salud, tal como los derivados de la soya, por ejemplo.

\section{Categorías más innovadoras en América Latina}

Los estudios mencionados clasifican en diez categorías los productos que más se han innovado en América Latina

1. Bebidas sin alcohol.

2. Productos de panificación.

3. Productos congelados.

4. Productos lácteos.

5. Productos para aperitivos.

6. Confitería o dulces.

7. Cereales.

8. Chocolates.

9. Condimentos y salsas.

10. Mermeladas frutas en sirope y producto sustentables.

Los productos muy clásicos ya no funcionan, aun cuando se trata de regresar a sabores de tipo tradicional y comidas que recuerdan a personas y familiares. Todos ellos entran y evolucionan con la relación calidad/precio o beneficio/precio.

La mezcla de géneros: la comida fusión o la utilización amplificada a nuevas categorías de productos con ingredientes exóticos permite aportar una nueva dimensión poco habitual con valor agregado. Por ejemplo, el jengibre en bebidas o productos lácteos.

Siguiendo sobre los estudios que tratan de identificar el nivel de aceptación en segmentos de población, resultan interesantes los 
resultados obtenidos por Verónica Mosquera Vásquez y Freddy Muñoz Gómez (2016), en su tesis sobre Validación del nivel de aceptación de comida rápida saludable en ejecutivos de la ciudad de Bogotá mediante la aplicación del modelo de Teoría de Comportamiento Planificado. Ellos destacan cómo la salud es considerada uno de los principales motores de innovación para la industria de alimentos, lo cual, según su estudio, ha creado una nueva línea de alimentos denominada Salud y Bienestar. Referenciando un trabajo de la Fundación Chile (2013), consideran que la demanda de aquellos consumidores interesados en alimentarse bien con comida rápida saludable, sería una excelente opción para satisfacer las necesidades nutricionales de poblaciones, como en este caso, los ejecutivos de la ciudad de Bogotá.

El estudio muestra el consumo de alimentos que aportan los nutrientes necesarios para un buen estado de salud, y previene enfermedades relacionadas con la nutrición, tales como la obesidad, la hipertensión, la anemia, la diabetes, entre otras. Esto fue posible al identificar el nivel de aceptación de comida rápida saludable en ejecutivos de la ciudad de Bogotá. Destacan los hábitos alimenticios de este segmento y los factores que motivan su compra. Al evaluar la aceptación de comida rápida saludable logran medir la intención de compra y determinan los lugares habituales en los que encuentran este tipo de comida en Bogotá y los precios ofrecidos.

\section{Estudios para fortalecer el sector agropecuario}

Los alimentos cumplen un papel importante en el fortalecimiento del sector agropecuario, y tienen efectos favorables en las familias de bajos ingresos. La pobreza es un aspecto ligado a los alimentos, por cuanto el mayor indicador de pobreza es la dificultad que tiene 
esta población de adquirir alimentos procesados en la ciudad y de tipo natural que llega del campo (Estrada-López, et al., 2013).

Estudios han insistido en que las pérdidas y desperdicio de alimentos en América Latina es uno de los factores de encarecimiento de los productos alimenticios. Sobre este tema en especial, se encuentra un estudio de la Organización de las Naciones Unidas para la Alimentación y la Agricultura-FAO (2015), en el cual se indica cómo los distintos gobiernos y el sector productivo de los países que forman parte de la Comunidad de Estados Latinoamericanos y Caribeños (CELAC), principal plataforma política de la región, ha tomado la reducción de Pérdidas y Desperdicios de Alimentos como línea de acción de su Plan de Acción para la Seguridad Alimentaria, Nutrición y Erradicación del Hambre 2025. En el documento se señalan experiencias nacionales, y en el aprovechamiento de subproductos. Resaltan la dificultad para reducir pérdidas y desperdicios de alimentos que se dan en los países de la región.

La FAO muestra en este informe evidencias de pérdidas y desperdicios de frutas y productos agropecuarios por efecto de manipulación y procesos de maduración, que hacen que estos pierdan valor y afecten la cadena de valor específico en algunos países. Tal problema se planteó en el marco de la Comunidad de Estados Latinoamericanos y Caribeños (CELAC) en enero de 2015, donde se aprobó en Costa Rica el Plan de Acción de la CELAC para la Seguridad Alimentaria, Nutrición y Erradicación del Hambre 2025. Este informe fue solicitado a la FAO por la CELAC, con el propósito de buscar soluciones contando con la colaboración de la Asociación Latinoamericana de Integración (ALADI), y la Comisión Económica para América Latina y el Caribe (CEPAL). 
Además de la pérdida de alimentos, la agricultura y sus productos derivados también han venido perdiendo peso en el PIB de las naciones. El sector industrial, inicialmente, y luego el sector terciario de servicio, han ocupado estos lugares en la economía de las naciones. Sin embargo, los productos del campo siguen teniendo importancia, por cuanto son enlaces entre la industria de alimentos, y otros derivados (agroindustria), y en los centros de consumo como materia prima para los centros comerciales de las grandes ciudades.

Es así como la ANDI (2015), una entidad que asocia a los industriales de Colombia, se ocupa del sector agropecuario, y dentro de su Balance del año 2015 en Colombia y las perspectivas del año 2016, considera que la economía colombiana tuvo como factores favorables la búsqueda de inversionistas para la ejecución de grandes proyectos de infraestructura; especialmente en vías de comunicación. Esto, ligado a los avances en el proceso de paz, le permitió al país mantener la tasa de inversión alrededor del $30 \%$ del PIB, y el reconocimiento de inversionistas nacionales e internacionales como un país con alto potencial. Consideran importante las propuestas para el sector rural, indicando la necesidad de tener estudios sobre las reformas estructurales que no dan espera, como son las desarrolladas en el marco de la misión rural y la comisión de expertos para la equidad y competitividad tributaria (Estrada-López, Saumett-España, y Sánchez, 2015).

De acuerdo con el estudio, esta organización señala que al gobierno le resulta complejo manejar el impacto del precio del petróleo y el aumento del dólar, por cuanto tiene que importar a precios más altos los insumos que afectan toda la economía. El cierre de 
la frontera con Venezuela, el endurecimiento en las condiciones de exportación hacia Ecuador y, por supuesto, la desaceleración en la economía mundial, tiene aspectos que deben ser manejados con cierto cuidado, como es la reforma tributaria y la inserción de la población desmovilizada a la economía nacional.

Continuando en las perspectivas de la agricultura en América Latina, la CEPAL (2015) publicó un documento en el cual analiza la evolución de los mercados financieros y macroeconómicos, en los cuales se mueve la agricultura en América Latina. Son cuatro capítulos en donde se hace un recorrido por los sectores como la agricultura, la pesca y los bosques. En ellos presentan las principales tendencias de las distintas regiones del subcontinente (Estrada-López, et al., 2013).

Dos capítulos son de gran interés, por cuanto se refiere a los ingresos de las personas que se dedican a los trabajos propios del campo rural y su acceso al mercado laboral. Esto, ligado a las políticas institucionales que buscan que la agricultura se convierta en una actividad competitiva y sostenible, mediante el apoyo de programas orientados al desarrollo del sector rural. Aquí se hace énfasis en los retos que debe afrontar este sector, y el apoyo gubernamental representado en políticas públicas y reorientación de gasto para lograr efectos a mediano plazo, que garanticen la sostenibilidad del sector.

En este mismo sentido, los indicadores para el seguimiento del plan publicado por la CEPAL (2015), le hace seguimiento a los principales planteamientos de los Ministros de Agricultura en la Cumbre de las Américas, realizada en la ciudad de Panamá 2003. 
Es una manera de hacer un estado de cuentas sobre los avances logrados en los últimos trece años, tomando un conjunto básico de indicadores para la agricultura, lo que lo convierte en un documento enriquecido que aporta elementos para garantizar la implementación de la Agenda Hemisférica, buscando la construcción de acercamientos importantes para fortalecer este sector, mediante estrategias nacionales que forman parte de un plan que incluya los problemas del agro propios de los países de la región.

Estas políticas se complementan con las ferias y muestras comerciales, como la realizada en el Centro Internacional de Negocios y Exposiciones de Bogotá-Corferias, del 8 al 11 de junio de 2016, en donde organizaciones de desarrollo alternativo presentan muestras de alimentos tipo exportación, con estándares y sellos de origen. Durante el evento se realizan presentaciones de libros de cocina, conferencias sobre la preparación de este tipo de alimentos y la manera de fortalecer las capacidades de las organizaciones, temas sobre el mercadeo y las nuevas tendencias del consumo de alimentos fortificados. Esta feria es muy importante para la industria de alimentos y se convierten un evento representativo de las industrias nacionales de América Latina sobre alimentos procesados, hortofruticultura, bebidas, maquinarias y equipamiento para esta industria; se puede considerar como una ventana para el desarrollo de productos y novedades en este campo (Alimentec, 2016).

En el campo académico, se encuentra una publicación de la UNAM (2014), coordinado por Gerardo Torres Salcido y Marcel Morales Ibarra, que trata sobre el agro en el siglo XXI. Es interesante por cuanto reúne los planteamientos de investigadores, empresarios, políticos y estudiantes. Es, a todas luces, un ejercicio de conver- 
gencia que busca acercamientos entre la academia y los actores interesados. Se resalta la apertura de las Ciencias Sociales, diagnosticando problemas sociales y alternativas de solución mediante el diálogo con los afectados.

Aquí el agro es entendido como el espacio básico para la producción de alimentos tanto en zonas rurales apartadas, como las que se encuentran cerca de los centros urbanos, ligadas a la agroindustria. En las zonas rurales se resalta que estas no solo producen alimentos, sino que realizan un conjunto de funciones que no siempre son reconocidas, tales como el mantener las tradiciones culturales que son únicas de la región. Son unidades económicas en pequeña escala, que junto con la agricultura o la producción pecuaria y forestal, generan opciones sobre el territorio que buscan el reconocimiento y la valoración del patrimonio, y la identidad cultural de la región; así, el paisaje, las formas de poblamiento, las costumbres, etc., son intangibles y pueden convertirse en una fuente de ingresos. Los alimentos tradicionales, las transformaciones de frutas al natural y el procesamiento artesanal le agregan un atractivo especial (Estrada-López, et al., 2015).

Sobre estos mercados emergentes, Francisco Morales Bermúdez (2015), presentó una ponencia en Lima, donde señala la posibilidad de potenciar el mercado de acuerdo al nuevo escenario mundial. Citando documentos del Banco Interamericano de desarrollo, (BID) "América latina, la próxima despensa global", señala que los países del subcontinente cuentan con los elementos para participar de la mayor producción alimentaria que requiere el mundo de aquí al año 2050. Para eso, México, Colombia, Perú y Chile deben establecer en forma conjunta cadenas de distribución, tiendas es- 
pecializadas, y supermercados en forma conjunta; salir al mundo con marcas propias y certificaciones de calidad, y la participación en ferias internacionales con marcas sectoriales.

Todo parece indicar que la vinculación a los mercados emergentes con propuestas novedosas y que logren interesar a consumidores y a inversionistas, es una alternativa para la producción de alimentos funcionales. El Merchandising y su evolución hacia los sectores de gran consumo es una opción a tener presente. Ana Iglesias Megías (2014) indica que a pesar de que esta técnica tiene sus orígenes desde que se comenzó a utilizar el comercio, a través de los años ha ido evolucionando y se convierte en un nuevo concepto que facilita la presentación y colocación de los productos al alcance de los consumidores.

La gran evolución que ha sufrido esta herramienta, sobre todo en los últimos años -señala la autora- le lleva a explicar las tendencias más novedosas y peculiares de esta técnica de marketing y lo que se espera de ella en el futuro. Se trata de mostrar cómo el merchandising logra impactar al consumidor actual, y cuáles son los factores a tener en cuenta para lograr el éxito con el uso de esta herramienta. Ella destaca la metodología que empleó, en donde combina la revisión de fuentes de documentación y las entrevistas a profundidad a expertos, lo cual le permite explicar el papel que juega el merchandising en el mundo empresarial actual y qué se espera de él en el futuro.

Volviendo a la evaluación de los programas para la Ciencia y Tecnologías Agropecuarias propuesta en Colombia, es necesario referenciar el documento de Colciencias (2005) Bases para la formula- 
ción del Programa Nacional de 2005-2015. En este documento se propone mejorar la productividad agrícola aprovechando un mayor rendimiento en la producción, disminución de los costos, mayor calidad y diversidad productiva con alta especialización y agregación de valor.

Se trata de hacer que los esfuerzos, tanto públicos como privados, se orienten hacia la consolidación de la cadena productiva, de manera que estas respondan a políticas y programas formulados por el Ministerio de Agricultura, fortaleciendo la cadena de valor y de agregar procesos de transformación de los productos de manera que se garantice la utilización óptima de las frutas y verduras cultivadas. Si se tienen en cuenta los avances en merchandising señalados, y se disminuyen las pérdidas por la manipulación y los cuidados con alimentos que tienen un tiempo corto para su consumo o los procesos que permiten una mayor duración, se tendrían unos mejores resultados en la condición de producción y en los ingresos de los trabajadores del campo.

Los alimentos funcionales son, de esta manera, una opción importante para el desarrollo y bienestar de la sociedad colombiana. Fuentes-Berrío, Acevedo y Gelvez (2015) realizaron una evaluación de alimentos funcionales que pueden aportar un valor adicional en nutrientes. Los resultados obtenidos indican que las exigencias de los consumidores son mayores, y la búsqueda de nuevos productos con funciones nutritivas son parte de sus hábitos de consumo. Esto posiblemente ha acelerado las inversiones que se requieren para su producción y comercialización, pero también se ha convertido en un mercado atractivo para nuevos inversionistas. Naturalmente que tienen grandes exigencias en materia de comunicación y pu- 
blicidad, en cuanto deben llegar a consumidores bien informados. Cada día aparecen nuevos productos con componentes activos, que proporcionan beneficios fisiológicos que van más allá de la satisfacción de necesidades nutricionales básicas, las que son canalizadas por mercados especializados, los que se han convertido en una fuente importante para el crecimiento del sector de alimentos.

El crecimiento de este sector, la creación de nuevos valores y la generación de puestos de trabajo, lleva a vincular a la agricultura orgánica con la industria y el sector de servicios, formando parte del mercado de alimentos y bebidas, pero con unas demandas de clientes que buscan algún componente es especial. Víctor J. Martín Cerdeño (2014) de la Universidad Complutense de Madrid se hace estas preguntas sobre el particular: ¿Qué ha cambiado en el mercado de alimentos en la última década? ¿Cuáles serían las tendencias de este mercado en los próximos años? Esto le permite sugerir treinta claves del mercado alimentario, revisando las que en el pasado se identificaron en la distribución y el consumo. Luego, ubicando esto en el contexto español actual, describe algunos aspectos de la demanda que lo llevan a un conjunto previsible de situaciones que tendrá el mercado de alimentos en los próximos años; son treinta puntos que el autor describe y recomienda tener en cuenta.

\section{ANÁLISIS DE LOS RESULTADOS}

Con la entrevista se reconstruyen los elementos que conforman los perfiles socioeconómicos de cada unidad de estudio y de su propietario, ubicados en la zona urbana y en el área rural de los municipios de Santa Lucía y Malambo, del departamento del Atlántico. Asimismo, la entrevista refleja la situación de los pequeños pro- 
ductores agrícolas. Esta información es importante para conocer la forma en que ellos han aplicado, en sus unidades productivas, los conceptos de administración. Aquí se puede captar cuál es la capacidad con que cuentan, cómo gestionan la calidad de sus productos y los aspectos más significativos para la marcha del negocio. La estrategia que emplean para garantizar el crecimiento del negocio y la manera de verificar los resultados obtenidos.

Para fortalecer el estudio, se utilizan también herramientas cuantitativas de muestra de población, tal como lo señala Tamayo (2008), quien entiende por población a la totalidad del fenómeno a estudiar, en donde tienen características comunes susceptibles de observación, hecho que da origen a los datos cuantificables de la investigación.

Esta segunda fase está orientada a evaluar las condiciones económicas y de mercado para la producción y comercialización de los productos elaborados, de tal forma que los resultados de las innovaciones propuestas puedan introducirse exitosamente en el mercado como proceso productivo. Así mismo se hace un análisis de la participación de los propietarios en las dos organizaciones vinculadas al proyecto; finalmente, en la tercera etapa, los resultados obtenidos darán origen a productos de investigación transferibles a la comunidad académica y diferentes sectores, entre ellos pequeños productores, cooperativas y comunidades del sector agroindustrial, los cuales tendrán la posibilidad de replicar los desarrollos logrados para incorporar mejoramiento tecnológico a sus procesos y, por ende, la diversificación de productos (Estrada-López H., 2008).

Con la información obtenida se puede establecer la forma en que 
ellos han aplicado en sus unidades productivas los principios de administración. Aquí se capta cuál es la capacidad con que cuentan, cómo gestionan la calidad de sus productos y los aspectos más significativos para la marcha del negocio. Es de resaltar las estrategias que emplean para garantizar el crecimiento del negocio, y la manera de verificar los resultados obtenidos con las estrategias empleadas.

Dos organizaciones participan directamente en el proyecto, y son las que orientan y agrupan a los propietarios de las pequeñas unidades productivas del estudio: Asofruma y Cooagrosur. Asofruma es la asociación de fruticultores de Malambo que se constituyó con el propósito de fortalecer la siembra, sostenimiento y cosechas de frutales. Estos son de corto, mediano y tardío rendimiento, tales como la guayaba, maracuyá, tomate, guanábana, plátano, yuca, hortalizas, tamarindo y demás frutales que se dan en la región del departamento del Atlántico. Algunos también combinan los cultivos de frutas con maderables y forestales.

Asofruma fue creada para la comercialización y transformación de productos agrícolas y, en este caso, se han aliado con la Cooperativa comercializadora de productos agrícolas del sur, Cooagrosur. El proyecto complementa sus productos actuales mediante la transformación de frutas y hortalizas en alimentos saludables. Las entrevistas se refieren a los asociados de estas dos organizaciones y fueron seleccionados de acuerdo a su situación actual para mostrar las características, su evolución y el manejo administrativo de pequeñas propiedades vinculadas al proyecto.

Las unidades productivas afiliadas a Asofruma que participan en el proyecto están conformadas por un propietario o varios propieta- 
rios de tipo familiar, que han logrado cultivar árboles frutales con el propósito de mejorar sus ingresos y obtener utilidades marginales de esta producción. Cada uno de ellos tiene una función dentro de la asociación y describen su negocio de manera particular, pero resaltando la vinculación a la asociación (Estrada-López, y Jiménez, 2012).

La entrevista muestra los tipos y formas de ver la unidad productiva. Estas se conciben, en un caso como el centro de la vida del propietario, otro que comparte los cuidados a cambio de dejar que utilicen la unidad en la cría de especies menores, indicándole cómo se atiende el cultivo de los frutales, y el propietario que concibe la unidad productiva como una empresa rentable, para lo cual es necesario combinar los cultivos de frutales con otras actividades pecuarias (Estrada-López, Martínez, y Ruiz, 2013).

Tabla 5

Formas como perciben su participación en Asofruma

\begin{tabular}{|c|c|c|c|c|c|}
\hline & & $\begin{array}{l}\text { Manuel } \\
\text { Donado }\end{array}$ & $\begin{array}{l}\text { Oscar } \\
\text { Arraut }\end{array}$ & $\begin{array}{l}\text { Manuel } \\
\text { Marquez }\end{array}$ & $\begin{array}{c}\text { Gustavo } \\
\text { Camargo }\end{array}$ \\
\hline 1 & $\begin{array}{l}\text { ¿Cómo } \\
\text { describe su } \\
\text { negocio? }\end{array}$ & $\begin{array}{l}\text { Actualmente } \\
\text { soy el re- } \\
\text { presentante } \\
\text { legal de la } \\
\text { Asociación de } \\
\text { Fruticultores } \\
\text { de Malambo, } \\
\text { Asofruma. Mi } \\
\text { finca se llama } \\
\text { San José; } \\
\text { además del } \\
\text { mango tengo } \\
\text { también otros } \\
\text { frutales como } \\
\text { son el nís- } \\
\text { pero, limón, } \\
\text { guanábana, } \\
\text { guayaba } \\
\text { agria. }\end{array}$ & $\begin{array}{l}\text { Soy el Te- } \\
\text { sorero de } \\
\text { Asofruma. } \\
\text { Y de esos } \\
\text { siete her- } \\
\text { manos hay } \\
\text { asociados } \\
\text { a Asofruma } \\
\text { dos más, el } \\
\text { difunto An- } \\
\text { tonio Arraut } \\
\text { y una hija de } \\
\text { él, Yanina, } \\
\text { serían los } \\
\text { dos asocia- } \\
\text { dos. }\end{array}$ & $\begin{array}{l}\text { Copropietario de } \\
\text { la finca San Martín, } \\
\text { soy productor de } \\
\text { mango asociado } \\
\text { a Asofruma; la } \\
\text { producción de } \\
\text { la finca se basa } \\
\text { prácticamente en } \\
\text { la producción de } \\
\text { mangos. }\end{array}$ & $\begin{array}{l}\text { Pertenezco a } \\
\text { la Asociación } \\
\text { de Fruticulto- } \\
\text { res Asofruma } \\
\text { desde que se } \\
\text { inició, enton- } \\
\text { ces ya había } \\
\text { establecido } \\
\text { en la finca } \\
\text { más o menos } \\
\text { una hectárea } \\
\text { de mango, } \\
\text { después se } \\
\text { estableció } \\
\text { hace seis } \\
\text { años. }\end{array}$ \\
\hline
\end{tabular}

Fuente: Elaboración propia. 
Cooagrosur es una cooperativa que se fortaleció en el proyecto de cultivadores y productores de guayaba y otros productos de alimentos. Es una organización que contribuye al mejoramiento social, económico y cultural de los asociados, y al desarrollo de la comunidad agrícola, en particular a las que están vinculadas con el procesamiento y mercadeo de productos como la guayaba. Esta organización, mediante la aplicación de métodos cooperativos y una eficaz administración, ha participado y promovido programas de educación empresarial, social y cooperativo para los socios. Es notable como afrontaron las inundaciones del sur del Atlántico y la lenta recuperación de esta zona del país.

Tabla 6

Formas como perciben su participación en Cooagrosur

\begin{tabular}{|c|c|c|c|c|c|}
\hline & & Fray Luis Pérez & Dorian Niño & Jesús María Ariza & Yairo Carreño \\
\hline 1 & $\begin{array}{l}\text { ¿Cómo } \\
\text { describe } \\
\text { su nego- } \\
\text { cio? }\end{array}$ & $\begin{array}{l}\text { Bueno, yo toda } \\
\text { la vida me de- } \\
\text { diqué a la pro- } \\
\text { ducción y co-- } \\
\text { mercialización } \\
\text { de guayaba al } \\
\text { fresco, en el } \\
\text { departamento } \\
\text { del Atlántico. } \\
\text { Cuando ya nos } \\
\text { agrupamos en } \\
\text { Cooagrosur, } \\
\text { nace un gran } \\
\text { proyecto que } \\
\text { era el fortale- } \\
\text { cimiento em- } \\
\text { presarial en la } \\
\text { parte de co-- } \\
\text { mercialización } \\
\text { y trasformación } \\
\text { de guayaba. }\end{array}$ & $\begin{array}{l}\text { Soy socio y } \\
\text { tesorero de } \\
\text { la cooperati- } \\
\text { va. La expe- } \\
\text { riencia y el } \\
\text { recorrido que } \\
\text { he tenido en } \\
\text { estos años; } \\
\text { nosotros } \\
\text { comenzamos } \\
\text { el proceso } \\
\text { gracias a la } \\
\text { Universidad } \\
\text { Simón Bolívar } \\
\text { con el SENA, } \\
\text { algo que } \\
\text { siempre he } \\
\text { destacado la } \\
\text { serie de ca- } \\
\text { pacitaciones } \\
\text { que nos han } \\
\text { brindado. }\end{array}$ & $\begin{array}{l}\text { Yo hago parte de } \\
\text { la junta adminis- } \\
\text { trativa, soy guaya- } \\
\text { bero, soy técnico } \\
\text { viverista, le doy } \\
\text { gracias al com- } \\
\text { pañero, Fray que } \\
\text { es un monstruo, } \\
\text { incomparable, un } \\
\text { monstruo. Partici- } \\
\text { pé en el negocio } \\
\text { de comercializa- } \\
\text { ción de guayaba, } \\
\text { y aprendí mucho } \\
\text { lo que es el co- } \\
\text { mercio. }\end{array}$ & $\begin{array}{l}\text { Soy productor, } \\
\text { hago parte de } \\
\text { la cooperativa, } \\
\text { en mi parcela } \\
\text { se produce } \\
\text { guayaba, } \\
\text { maíz, limón, } \\
\text { mango. }\end{array}$ \\
\hline
\end{tabular}

Fuente: Elaboración propia. 
Como se puede captar en los cuadros anteriores, se reconoce el conocimiento adquirido de las entidades aplicado a su labor diaria; un buen ejemplo de esto es el entrenamiento en la comercialización de las frutas. Koontz, Weihrich y Cannice (2012) sostienen que para que sea efectivo el asesoramiento y la orientación (coaching) debe hacerse en un clima de confianza entre quienes están en desarrollo; se requiere paciencia y juicio para delegar autoridad, reconocer y dar crédito por el trabajo bien hecho. Los asesores y orientadores ejecutivos (coachers) efectivos desarrollarán las fortalezas potenciales y los ayudarán a superar sus debilidades. El asesoramiento y la orientación (coaching) requieren tiempo, pero si se hacen bien, ahorrarán tiempo y dinero, además de que impedirán errores costosos en pequeñas unidades de producción (Castañeda, Ruiz, Guardiola, y Estrada-López, 2010).

Refiriéndose al desarrollo administrativo, sostienen que debe utilizar un enfoque de sistema abierto que responda a las necesidades y exigencias del ambiente externo (Koontz, Weihrich y Cannice, 2012). En esto se reconoce la existencia de una creciente percepción de la necesidad de programas de capacitación, específicamente diseñados para los miembros de grupos minoritarios y con capacidades diferentes.

La Cooperativa es una organización con mucha experiencia, y su trabajo en alianza con Asofruma puede ser de gran utilidad para conseguir los resultados esperados en el proyecto de confitería saludable. En este caso es importante tener en cuenta la experiencia adquirida por estos líderes en la transformación o procesamiento para los productos de origen agrícola y pecuario de los asociados. 
La Cooperativa recibe de los asociados los productos agrícolas de las cosechas para su mercadeo, además de promover y ejecutar programas de fomento agrícola, desarrollo tecnológico y productivo, infraestructura productiva y todos aquellos que tengan por finalidad aumentar la productividad y competitividad de las parcelas campesinas y el bienestar de las familias (Reales, Estrada-López, 2012).

Lo anterior se puede apreciar en las entrevistas realizadas a propietarios de las unidades productivas asociados a esta organización, en donde conciben el negocio como algo a lo que le han dedicado la mayor parte de su vida, y el contacto con entidades como el SENA que les ha permitido superar los problemas que han pasado. Un entrevistado que forma parte de la junta administrativa se considera que, además de ser cultivador de guayaba, es técnico en viveros, reconoce que en la Cooperativa hay personas muy capaces que le han enseñado sobre el negocio de comercialización de guayaba, plátano, limón y ahuyama que también cultiva. En la entrevista se refiere a la forma como afrontaron el desastre que les produjo la inundación del 2010 ... se realizaron los viveros y se seleccionaron las semillas empleando las buenas prácticas agrícolas que aprendieron.

\section{Evolución del negocio}

Estas han evolucionado siguiendo una tradición familiar; se trata de personas que se han dedicado a cultivar la tierra desde hace muchos años, pero que por diferentes razones se han retirado hacia otros negocios (Estrada-López y Jiménez, 2012).

De acuerdo a un entrevistado, el negocio ha evolucionado, de la 
donación de un familiar al cultivo de mango que le propuso ASOFRUMA. Uno de los problemas que afecta es la falta de lluvia. Ellos han tratado de obtener agua mediante pozos subterráneos que les permitan regar los árboles frutales y garantizar las cosechas. Es destacable la forma en la que afrontan los problemas, tal como lo expresa uno de los entrevistados. "De los 100 palos de mango de hilaza, se murieron aproximadamente unos 5 en este verano tremendo que hubo, el verano pasado afectó mucho a los palos de mango ya establecidos, se han sembrado dos hectáreas más, una de hace seis años y la otra de dos años, que ya está produciendo mango, pero no en cantidades; pero ya tengo uno que otro de mango injertado". Detalles sobre esta evolución del negocio, de acuerdo a la entrevista, se pueden encontrar en la Tabla 7.

Tabla 7

Evolución del negocio de asociados a Asofruma

\begin{tabular}{|c|c|c|c|c|c|}
\hline & & $\begin{array}{l}\text { Manuel } \\
\text { Donado }\end{array}$ & Óscar Arraut & Manuel Márquez & Gustavo Camargo \\
\hline 4 & $\begin{array}{l}\text { ¿Cómo se } \\
\text { inició este } \\
\text { negocio y } \\
\text { hace cuán- } \\
\text { to (motiva- } \\
\text { ciones, ex- } \\
\text { pectativas, } \\
\text { logros)? }\end{array}$ & & $\begin{array}{l}\text { Una dona- } \\
\text { ción que } \\
\text { nos hizo una } \\
\text { tía que nos } \\
\text { crió que no } \\
\text { tenía hijos y } \\
\text { nos regaló } \\
\text { esa finca; } \\
\text { mi hermano } \\
\text { se asoció a } \\
\text { ASOFRUMA } \\
\text { y vio que el } \\
\text { momento } \\
\text { era el mango } \\
\text { de hilaza } \\
\text { hace dos } \\
\text { años. }\end{array}$ & $\begin{array}{l}\text { Desde niño siem- } \\
\text { pre me gustó } \\
\text { estar en el campo } \\
\text { y vi que era una } \\
\text { oportunidad, la } \\
\text { finca, era de mi } \\
\text { papá y el único } \\
\text { que quedó en } \\
\text { la finca fui yo } \\
\text { porque mis her- } \\
\text { manos están por } \\
\text { fuera y yo soy el } \\
\text { único que le ha } \\
\text { puesto el pecho. }\end{array}$ & \\
\hline
\end{tabular}

Fuente: Elaboración propia.

El negocio de cultivos de los socios de Cooagrosur también viene de tradición familiar. En la entrevista se nota que se trata de un 
negocio que tenían sus padres y luego pasa a los actuales propietarios. Es interesante la forma en que se han sostenido a pesar de los problemas, tal como lo expresa un entrevistado: "Mi papá era agricultor y mi negocio empezó con mi suegro, mi suegro tenía una parcela y también él se dedicaba a la comercialización de maíz Un día cualquiera me llevó al mercado de Barranquillita y me di cuenta que la guayaba tenía bastante salida. Bueno, me fui integrando, mi papá se dedicaba a sembrar yuca, maíz, batata, ahuyama y esas cosas; pero cuando veo el ambiente que tiene la guayaba, me dediqué entonces a sembrar y a hacer mis semilleros, y así fue que me enamoré de ese cultivo" (Ver Tabla 8).

Tabla 8

Evolución del negocio de afiliados a Cooagrosur

\begin{tabular}{|c|c|c|c|c|c|}
\hline & & $\begin{array}{l}\text { Fray Luis } \\
\text { Pérez }\end{array}$ & Dorian Niño & $\begin{array}{c}\text { Jesús María } \\
\text { Ariza }\end{array}$ & Yairo Carreño \\
\hline 4 & $\begin{array}{l}\text { ¿Cómo se } \\
\text { inició este } \\
\text { negocio } \\
\text { y hace } \\
\text { cuánto } \\
\text { (motiva- } \\
\text { ciones, } \\
\text { expec- } \\
\text { tativas, } \\
\text { logros)? }\end{array}$ & $\begin{array}{l}\text { Mi papá era } \\
\text { agricultor y mi } \\
\text { negocio em- } \\
\text { pezó con mi } \\
\text { suegro; tenía } \\
\text { una parcela } \\
\text { y también él } \\
\text { se dedicaba } \\
\text { a la comer- } \\
\text { cialización } \\
\text { de maíz. Una } \\
\text { vez que fui al } \\
\text { mercado y me } \\
\text { di cuenta que } \\
\text { la guayaba se } \\
\text { vendía y me } \\
\text { enamoré de } \\
\text { ese cultivo. }\end{array}$ & $\begin{array}{l}\text { Desde que ten- } \\
\text { go uso de ra- } \\
\text { zón, desde que } \\
\text { yo iba en el } \\
\text { anca del burro } \\
\text { con mi papá al } \\
\text { monte, todo el } \\
\text { tiempo nos he- } \\
\text { mos mantenido } \\
\text { con los cultivos, } \\
\text { por lo menos, } \\
\text { el sembraba } \\
\text { y uno viendo } \\
\text { ahí, viendo } \\
\text { se aprende, } \\
\text { ayudando a mi } \\
\text { papá, yo me } \\
\text { dedicaba al rie- } \\
\text { go, para evitar } \\
\text { la pérdida de } \\
\text { árboles. }\end{array}$ & $\begin{array}{l}\text { En el caso } \\
\text { mío, mi papá } \\
\text { era un hom- } \\
\text { bre polifacé- } \\
\text { tico, o tenía } \\
\text { ganado pero } \\
\text { amaba más } \\
\text { la agricultura } \\
\text { que al ganado } \\
\text { y el caso mío } \\
\text { es lo mismo, } \\
\text { yo amo más } \\
\text { la agricultura } \\
\text { que al gana- } \\
\text { do, Fray que } \\
\text { me decía: } \\
\text { "siembra gua- } \\
\text { yaba" y me } \\
\text { di cuenta que } \\
\text { el negocio de } \\
\text { la guayaba es } \\
\text { rentable. }\end{array}$ & $\begin{array}{l}\text { La finca es de } \\
\text { mi papá, todo } \\
\text { el tiempo ha } \\
\text { sido produc- } \\
\text { tor, todo el } \\
\text { tiempo ha } \\
\text { sembrado } \\
\text { yuca, ahuya- } \\
\text { ma, y veíamos } \\
\text { a unos seño- } \\
\text { res por allá } \\
\text { que hacían } \\
\text { plata con la } \\
\text { guayaba, y } \\
\text { eso me emo- } \\
\text { cionó y ahí es- } \\
\text { tamos con la } \\
\text { guayaba que } \\
\text { es el mejor } \\
\text { negocio. }\end{array}$ \\
\hline
\end{tabular}

Fuente: Elaboración propia. 


\section{Aspectos misionales}

Importante para los asociados a Asofruma es practicar ciertos valores como la perseverancia, porque les produce satisfacción cuando logran vencer los tropiezos y conseguir lo que se han propuesto. Un principio de la asociación que se reconoce es la solidaridad, porque allá como no se tiene para producir, se comparte el trabajo de manera que los productos se intercambian, "... ellos me dan yuca, y con eso ayudo un poco a la gente en su modo de vivir, tengo una persona que es la encargada de la finca que trabaja también para su propio negocio de cría".

Tabla 9

Aspectos misionales de los afiliados a Asofruma

\begin{tabular}{|c|c|c|c|c|c|}
\hline & & $\begin{array}{l}\text { Manuel } \\
\text { Donado }\end{array}$ & Óscar Arraut & $\begin{array}{l}\text { Manuel } \\
\text { Márquez }\end{array}$ & Gustavo Camargo \\
\hline 7 & $\begin{array}{l}\text { ¿Qué valores } \\
\text { y principios } \\
\text { han guiado } \\
\text { su quehacer } \\
\text { en este nego- } \\
\text { cio? }\end{array}$ & $\begin{array}{l}\text { Perseveran- } \\
\text { cia, porque } \\
\text { siente sa- } \\
\text { tisfacción } \\
\text { cuando } \\
\text { uno logra } \\
\text { vencer los } \\
\text { tropiezos y } \\
\text { conseguir } \\
\text { lo que uno } \\
\text { quiere. }\end{array}$ & $\begin{array}{l}\text { Solidaridad } \\
\text { porque allá en } \\
\text { la finca no te- } \\
\text { nemos cómo } \\
\text { producirla, se } \\
\text { la doy a los } \\
\text { campesinos } \\
\text { por dos años } \\
\text { me limpian, } \\
\text { ellos me dan } \\
\text { yuca, y con } \\
\text { eso ayudo un } \\
\text { poco a la gen- } \\
\text { te en su modo } \\
\text { de vivir; tengo } \\
\text { una persona } \\
\text { que es la en- } \\
\text { cargada de la } \\
\text { finca. }\end{array}$ & $\begin{array}{l}\text { La humil- } \\
\text { dad, la } \\
\text { honradez, } \\
\text { ser alguien } \\
\text { positivo } \\
\text { para la } \\
\text { sociedad y } \\
\text { no ser una } \\
\text { carga para } \\
\text { la socie- } \\
\text { dad. }\end{array}$ & $\begin{array}{l}\text { La mayor motiva- } \\
\text { ción de muchos de } \\
\text { los que estamos } \\
\text { aquí es la tranqui- } \\
\text { lidad y la paz, de } \\
\text { pronto uno llega } \\
\text { a hacerla producir, } \\
\text { es difícil, pero la } \\
\text { tranquilidad que le } \\
\text { da una finca, no se } \\
\text { consigue en otra } \\
\text { parte. }\end{array}$ \\
\hline
\end{tabular}

Fuente: Elaboración propia.

En el cuadro anterior se muestran las habilidades que los propietarios resaltan como valores y características personales, las que se reflejan en: el deseo de administrar bien, la capacidad de comu- 
nicar con empatía, la integridad y la honestidad, y la experiencia previa, consideradas como características muy importantes.

Para algunos, la humildad, la honradez, ser alguien positivo para la sociedad y no ser una carga para los demás, es un principio que guia su comportamiento... "la mayor motivación de muchos de los que estamos aquí es la paz y la seguridad que tenemos al compartir el espacio y ayudarnos para evitar los brotes de violencia que azotan al país".

Hacer producir la tierra es difícil, pero la tranquilidad que le da una finca no se consigue en otra parte. Realmente ellos no ven como un valor importante el liderazgo, por cuanto están pensando que la solidaridad les garantiza que las personas asuman sus compromisos sin tener que controlarlos. Es característico en este tipo de negocio depender más del día a día que planear con anticipación las actividades a realizar. Tienen claro que las personas que le colaboran deben recibir algún incentivo, y este, por lo general, es compartir con las personas mediante mercados, compra de libros para los hijos, ceder una parte de la cosecha, facilitarles para que tengan su propio negocio dentro de la propiedad y les pagan para que puedan sostener a sus familiares.

Los propietarios que tienen éxito muestran un fuerte deseo de administrar, de influir en otros y lograr resultados mediante los esfuerzos de equipo con sus colaboradores, por lo general, familiares. Muchas personas quieren los privilegios del propietario del negocio, que incluyen ingresos mayores, pero carecen de la motivación básica para alcanzar resultados al crear un ambiente en el que las personas trabajen juntas hacia metas comunes. El deseo 
de administrar requiere esfuerzo, tiempo, energía y, casi siempre, largas horas de trabajo.

En estos aspectos misionales se pueden observar diferencias entre las dos organizaciones. Mientras que los afiliados a Asofruma tienen varios principios, los de Cooagrosur se rigen por un solo principio, que es el respeto y tienen una visión más completa sobre la función que debe cumplir un líder (Estrada-López, Saumett-España, y Montenegro, 2017).

Tabla 10

Aspecto misional de los afiliados a Cooagrosur

\begin{tabular}{|c|c|c|c|c|c|}
\hline & & $\begin{array}{l}\text { Fray Luis } \\
\text { Pérez }\end{array}$ & Dorian Niño & $\begin{array}{c}\text { Jesús María } \\
\text { Ariza }\end{array}$ & Yairo Carreño \\
\hline 7 & $\begin{array}{l}\text { ¿Qué } \\
\text { valores y } \\
\text { principios } \\
\text { han guiado } \\
\text { su queha- } \\
\text { cer en este } \\
\text { negocio? }\end{array}$ & Respeto. & $\begin{array}{l}\text { Respeto y } \\
\text { amor. El buen } \\
\text { líder es aquel } \\
\text { que escucha, } \\
\text { y acepta } \\
\text { sugerencias. } \\
\text { Yo siempre } \\
\text { escucho y } \\
\text { puedo estar } \\
\text { trabajando } \\
\text { con personas } \\
\text { menores que } \\
\text { yo y acepto } \\
\text { sugerencias. }\end{array}$ & $\begin{array}{l}\text { Lo más lindo } \\
\text { que existe es } \\
\text { la tolerancia y } \\
\text { apartar el rencor } \\
\text { para ser feliz, el } \\
\text { que aparta el } \\
\text { rencor vive feliz } \\
\text { y el que es tole- } \\
\text { rante vive feliz } \\
\text { por eso yo vivo } \\
\text { feliz. }\end{array}$ & Respeto. \\
\hline
\end{tabular}

Fuente: Elaboración propia.

Para ellos, el líder debe escuchar y aceptar sugerencias; respetar las opiniones de las personas que trabajan con ellos, lo que han logrado mediante la experiencia, ya que reconocen que han aprendido de personas que ellos en principio creían que sabían menos.

Esta concepción del líder y sus valores está conectada con la capacidad de comunicarse. Esta exige sobre todo empatía, que es la capacidad de comprender los sentimientos de otra persona y hacer frente a los aspectos emocionales de la comunicación. 
La habilidad de comunicarse es importante en grupos pequeños, y los trabajadores del campo que por razones del trabajo están aislados uno de otro, su forma de comunicarse debe ser efectiva, es decir, la comunicación con personas de la misma unidad productiva; sin embargo, para el propietario, esta le permite dar instrucciones y trabajar junto con sus colaboradores para enseñar los procedimientos que son esenciales.

En la comercialización, saber interactuar con los clientes y tener una comunicación efectiva se vuelve cada vez más importante, es decir, aquella que se realiza no solo en un ambiente laboral, sino también con personas importantes para el negocio, como son: clientes, proveedores, gobierno, comunidad en general y socios de la Cooagrosur o de Asofruma.

Otra cualidad que es indispensable para lograr buenos negocios y mantener una buena relación laboral, la consiguen los propietarios cuando son moralmente íntegros y dignos de confianza. Ser reconocidos como personas íntegras supone honestidad en asuntos de dinero y el trato con otros, mantener su palabra, tener fuerza de carácter y un comportamiento acorde con los estándares éticos.

Son estas cualidades que han sido reseñadas en las entrevistas, y cada propietario se siente orgulloso no solo de escucharlas en sus negociaciones, sino que lo puede captar en las personas que trabajan junto y realizan algún tipo de transacción con él.

\section{Planeación estratégica}

El progreso de la unidad productiva está íntimamente ligado a la capacitación, la visión sobre el desarrollo y los ajustes a los cambios 
que ocurren en su entorno. Se preparan para ir un paso más adelante $y$, en algunos casos, adelantarse a los hechos, es decir, se preparan para un futuro próximo. Esto supone la capacidad para pronosticar qué competencias demandarán los cambios de tecnología y métodos. Por ejemplo, quizá vuelva a haber sequías, y esto requiere que los administradores estén capacitados no solo en los aspectos técnicos de su conservación, sino en la planeación relacionada con la provisión de agua a mediano y largo plazo, buscando siempre la solución creativa de problemas. A partir de este nuevo milenio, la capacitación en negocios está conectada con el manejo de negocios electrónicos (e-business); y asimismo, especialmente para estar informado de los precios y de nuevas formas de cultivar o procesar las frutas. El uso del computador está en los programas de capacitación, su efecto en el campo de los negocios móviles e inalámbricos ( $m$-business) ya no son desconocidos para los propietarios de los cultivos de frutas, especialmente sus hijos que demuestran un interés especial por dominar tal tecnología.

Así, los cambios creados por el ambiente externo, deben integrarse en los planes de capacitación de la unidad productiva, con un enfoque en el presente y futuro, planes contingentes no solo a las necesidades de capacitación, sino también a los diversos enfoques disponibles para aumentar los conocimientos de los propietarios. El estado de equilibrio que los propietarios buscan con fuerzas que empujan hacia el cambio, por una parte, y fuerzas que se resisten a este, al intentar mantener el statu quo, son reactivos frente a la situaciones que necesitan para progresar y avanzar aprovechando las capacidades de estas unidades productivas.

Muchas veces no se capta que los cambios se inician cuando las 
fuerzas que tratan de cambiar una situación de equilibrio rompen y su tendencia es desbordar e incrementar las fuerzas impulsoras; de hecho, esto produce movimientos que incrementan la resistencia al reforzar las fuerzas restrictivas. El enfoque más usual es que casi siempre es más efectivo reducir o eliminar las fuerzas restrictivas y luego ir a un nuevo nivel de equilibrio. Para el caso de las organizaciones que agrupan los propietarios de estas unidades, los cambios se expresan en políticas y proyectos que logran superar la resistencia, cuando los que podrían ser afectados se comprometen y participan en ellos.

Los propietarios consideran el trato entre personas como esencial para afrontar los cambios que se vienen en el entorno; han observado que al tratar bien a las personas estas los respetan y los consideran... "es bonito cuando le dicen a uno que lo admiran, y eso a uno lo enorgullece, aunque uno tampoco con escuchar una frase de esas se puede ir al cielo, porque de allá como se descuide se da una caída y tiene uno que saber entender a la persona". Sugieren el diálogo y saber aceptar cuando se equivocan. Esto a su juicio los hace más humanos y no les cuesta nada. "Yo he sabido llevar las cosas, los hijos míos cuando estaban conmigo, yo les enseñé, por ejemplo, en el proceso de la guayaba, yo les enseñé a vecinos que tenían miedo y no sabían cómo sanear la guayaba, no eran muy estrictos, la guayaba mía se vendía sola en Barranquilla, en chicha o en lo que fuera se vendía". Esta persona fue un líder que se preocupó por la calidad de la guayaba y les enseñó a sus compañeros de la cooperativa a clasificar la guayaba, todo lo que enseñó, hoy se lo reconocen, cuando se refieren a este líder, lo hacen con respeto, y los investigadores cuando hablan con él, encuentran que es una persona con mucho conocimiento sobre el tema de los cultivos, y 
notan que muchos productores le siguen y solicitan sus consejos para tomar decisiones que son importantes en su negocio.

Tabla 11

Cómo planean las actividades los afiliados de Cooagrosur. www.purex.com

\begin{tabular}{|c|c|c|c|c|c|}
\hline & & $\begin{array}{c}\text { Fray Luis } \\
\text { Pérez }\end{array}$ & Dorian Niño & Jesús María Ariza & $\begin{array}{c}\text { Yairo } \\
\text { Carreño }\end{array}$ \\
\hline 9 & $\begin{array}{l}\text { ¿Cómo } \\
\text { se pla- } \\
\text { nea el } \\
\text { día a día } \\
\text { de este } \\
\text { negocio? }\end{array}$ & $\begin{array}{l}\text { El día ante- } \\
\text { rior plani- } \\
\text { fico lo que } \\
\text { haré hoy. }\end{array}$ & $\begin{array}{l}\text { Desde que usted } \\
\text { llega a la finca } \\
\text { usted ve la nece- } \\
\text { sidad prioritaria, } \\
\text { que si hay mucha } \\
\text { maleza o si la gua- } \\
\text { yaba tiene plaga. } \\
\text { En el momento } \\
\text { gue uno llega a la } \\
\text { finca y va mirando } \\
\text { los cultivos todo } \\
\text { se va craneando y } \\
\text { sabe uno qué es lo } \\
\text { que hay que atacar } \\
\text { primero. }\end{array}$ & $\begin{array}{l}\text { Un día antes yo } \\
\text { digo: "mañana voy } \\
\text { para el monte y me } \\
\text { pongo en esto y } \\
\text { eso", ya yo llevo en } \\
\text { el perfil qué es lo } \\
\text { que voy a hacer, no } \\
\text { voy a esperar lle- } \\
\text { gar para entonces } \\
\text { quedarme mirando } \\
\text { para ver por dónde } \\
\text { voy a empezar; } \\
\text { no, no, yo llego y } \\
\text { enseguida arran- } \\
\text { co porque ya eso } \\
\text { viene del día antes } \\
\text { o en la noche. Y si } \\
\text { yo llego y hay otra } \\
\text { labor primordial, } \\
\text { cambio el chip. }\end{array}$ & $\begin{array}{l}\text { Cuando } \\
\text { llego a la } \\
\text { finca. }\end{array}$ \\
\hline
\end{tabular}

Fuente: Elaboración propia.

Cooagrosur tiene una mayor experiencia en la planeación de actividades que deben orientar el negocio de la producción de frutas y hortalizas. En las entrevistas se pone de manifiesto cómo planifican el día a día de este negocio. Para uno, cada día se puede planear un día antes; para otros es necesario revisar las necesidades prioritarias que presenta el cultivo, se trata de retirar la maleza y asegurarse que el cultivo no tenga plaga. Es un proceso que se inicia cuando se examina el cultivo y se empieza a decidir qué debe atenderse primero. Por lo general se trata de las plagas, por cuanto estas afectan directamente a las plantas, pero la maleza también requiere ser eliminada para obtener una planta sana. "Un día antes yo digo: mañana voy para el monte y me pongo en esto y eso, ya 
yo llevo en el perfil qué es lo que voy a hacer, no voy a esperar llegar para entonces quedarme mirando para ver por dónde voy a empezar; no, yo llego y enseguida arranco porque ya eso viene del día antes o en la noche. Y si yo llego y hay otra labor primordial, cambio el chip".

Asociarse es la mejor idea que han tenido para mejorar el negocio; es la apreciación que tienen los afiliados a Asofruma. Ellos consideran que los funcionarios de la asociación son una garantía para comercializar sus productos en el mercado de la ciudad. Sobre la pregunta por su mejor momento, la mayoría no la contestó, probablemente porque no se han detenido a pensar qué cosas le han funcionado en pasado y cuáles no han tenido éxito. Tal como lo plantea un copropietario, la mejor idea fue conseguir la personería jurídica de la asociación, puesto que era una aspiración que compartían y se había materializado.

Ambas organizaciones tienen planes para el futuro del negocio, los miembros de la asociación tienen claro cuáles serían sus metas a corto y mediano plazo, en donde se propone "Tenerle toda la tierra sembrada en frutales a mis nietos e hijos con su sistema de riego"; son conscientes de que para poder mantenerse en el negocio deben buscar el punto de equilibro, que ella misma se sostenga y produzca. También lograr la transformación del mango como posible estrategia de crecimiento.

Los afiliados a Cooagrosur expresan que la mejor idea que se les ocurrió para mejorar el negocio y que les ha funcionado, es la de haberse cooperado. Reconocen que no ha resultado fácil fortalecer la organización, pero los resultados les han demostrado la impor- 
tancia de haber constituido la Cooperativa para el crecimiento de su negocio. "En la Cooperativa estamos juntos, pero no revueltos, nadie molesta los productos de las parcelas de los compañeros, y ¿Por qué juntos? Para defendernos de la comercialización, para conseguir las cosas, somos más rentables, producimos más, a eso es a lo que nosotros le andamos apostando, tener una muy buena calidad de vida".

Tabla 12

Planeación que realizan los asociados a Asofruma

\begin{tabular}{l|l|l|l|l|l}
\hline \multicolumn{2}{l|}{} & Manuel Donado & Oscar Arraut & Manuel Marquez & $\begin{array}{l}\text { Gustavo } \\
\text { Camargo }\end{array}$ \\
\hline 13 & $\begin{array}{l}\text { ¿Cuáles } \\
\text { son los } \\
\text { planes } \\
\text { que tie- } \\
\text { ne para } \\
\text { el nego- } \\
\text { cio en el } \\
\text { futuro? }\end{array}$ & $\begin{array}{l}\text { Tener toda la } \\
\text { tierra sembrada } \\
\text { en frutales a mis } \\
\text { nietos e hijos } \\
\text { con su sistema } \\
\text { de riego y Dios } \\
\text { me permita } \\
\text { Ilegar allá. }\end{array}$ & $\begin{array}{l}\text { El futuro es } \\
\text { buscar el pun- } \\
\text { to de equi- } \\
\text { libro y que } \\
\text { ella misma se } \\
\text { sostenga y } \\
\text { que produz- } \\
\text { ca. También } \\
\text { lograr con la } \\
\text { universidad } \\
\text { la transfor- } \\
\text { mación del } \\
\text { mango y sería } \\
\text { otro punto } \\
\text { que tendría- } \\
\text { mos. }\end{array}$ & & $\begin{array}{l}\text { También } \\
\text { lograr un } \\
\text { punto de } \\
\text { equilibrio } \\
\text { para mi } \\
\text { finca. }\end{array}$ \\
& & & & \\
\hline
\end{tabular}

Fuente: Elaboración propia.

La Cooperativa es una organización que, de acuerdo a su líder, les está garantizando la compra de sus productos a un mejor precio y proyecta los valores de los propietarios de estas unidades productivas. Es innegable el orgullo de pertenecer a la Cooperativa expresado en la entrevista: "Le voy a poner un ejemplo: si usted sale a buscar una organización campesina en toda Colombia, así como nosotros que tenemos entre una hectárea y dos hectáreas, 
es raro que vaya a encontrar una organización como la que nosotros tenemos en el departamento del Atlántico". Es decir, se trata de productores en pequeña escala que buscan obtener beneficio con predios muy pequeños, lo que resulta muy difícil, por cuanto el minifundio por lo general es poco productivo, y los costos se elevan por la poca capacidad de inversión que tienen los propietarios, considerados de manera individual.

Tabla 13

Planeación que realizan los asociados a Cooagrosur

\begin{tabular}{|c|c|c|c|c|c|}
\hline & & Fray Luis Pérez & Dorian Niño & Jesús Ariza & Yairo Carreño \\
\hline 11 & $\begin{array}{l}\text { ¿Cuáles } \\
\text { han sido } \\
\text { las mejores } \\
\text { ideas que } \\
\text { se le han } \\
\text { ocurrido } \\
\text { para mejo- } \\
\text { rar el nego- } \\
\text { cio (cuáles } \\
\text { funcionaron } \\
\text { y cuáles no, } \\
\text { se le realizó } \\
\text { seguimien- } \\
\text { to)? }\end{array}$ & $\begin{array}{l}\text { El habernos coo- } \\
\text { perado. No ha sido } \\
\text { nada fácil y está } \\
\text { demostrado que } \\
\text { lo mejor que hay } \\
\text { es la organización, } \\
\text { es la cooperación. } \\
\text { En la Cooperativa } \\
\text { estamos juntos, } \\
\text { pero no revueltos, } \\
\text { producimos más, } \\
\text { a eso es a lo que } \\
\text { nosotros le anda- } \\
\text { mos apostando, } \\
\text { tener una muy } \\
\text { buena calidad de } \\
\text { vida. Le voy a po- } \\
\text { ner un ejemplo si } \\
\text { usted sale a buscar } \\
\text { una organización } \\
\text { campesina en toda } \\
\text { Colombia así como } \\
\text { nosotros que esta- } \\
\text { mos de } 1 \text { hectárea, } \\
2 \text { hectáreas. Es raro } \\
\text { que vaya a encon- } \\
\text { trar una organiza- } \\
\text { ción como la que } \\
\text { nosotros tenemos } \\
\text { en el departamen- } \\
\text { to del Atlántico. }\end{array}$ & Asociarnos. & Asociarnos. & Asociarnos. \\
\hline
\end{tabular}

Fuente: Elaboración propia.

Otra cuestión importante que resalta es la vinculación a políticas de fomento para el sector agropecuario, en donde las entidades 
territoriales hacen inversiones para fortalecerlo con propuestas de mejora de tipo colectivo. "En estos días nos van a dar otro activo, nos van a dar otro carro a través de la gobernación, no me lo van a entregar a mí, no me lo voy a llevar para mi casa; me lo van a entregar porque estamos asociados a través de una Cooperativa y estamos haciendo las cosas bien". Esto expresa el líder de la Cooperativa. Entre los planes para el futuro se piensa que este se puede sacar adelante con el apoyo de todos los cooperados. Para ellos es claro que la cooperativa es un buen aliado y un ente que les protege. Por esto, su cliente más importante es los mercados campesinos, en donde obtienen los mejores precios, y la planta procesadora en donde tienen cifradas sus mayores posibilidades.

\section{Estrategias para proyectar la unidad productiva}

Para proyectar la unidad productiva es indispensable que los propietarios asuman con responsabilidad el desarrollo de la capacidad de análisis y solución de problemas. Entender que detrás de cada problema se esconde una oportunidad. Es decir, debe ser capaz de separar los problemas de las oportunidades y proyectar su negocio analizando las situaciones tal como se presentan, y ver las oportunidades de una sola mirada, calcular sus posibilidades y actuar antes que se pierdan. En otras palabras, los propietarios son capaces de identificar problemas, analizar situaciones complejas y plantear soluciones a los problemas encontrados, explotar las oportunidades que se presentan. Saber analizar el ambiente e identificar, mediante un proceso racional, los factores que interfieren con las oportunidades. Así, se utilizarán las capacidades analíticas para encontrar las necesidades de clientes actuales o potenciales, y luego satisfacerlas con un producto o servicio. Se ha demostrado ampliamente que este enfoque de buscar oportunidades puede separar el éxito del fracaso. 
En el estudio, las estrategias para proyectar el crecimiento de la unidad productiva presentan algunas diferencias entre las dos asociaciones. En Asofruma, el representante legal responde solo a la primera pregunta sobre la competencia, tal vez no están preparados para participar en las dinámicas propias de este mercado.

Tabla 14

Estrategias de proyección para la unidad productiva de los asociados a Asofruma

\begin{tabular}{|c|c|c|c|c|c|}
\hline & & Manuel Donado & Óscar Arraut & $\begin{array}{l}\text { Manuel } \\
\text { Márquez }\end{array}$ & $\begin{array}{l}\text { Gustavo } \\
\text { Camargo }\end{array}$ \\
\hline 15 & $\begin{array}{l}\text { ¿Quiénes } \\
\text { son su } \\
\text { compe- } \\
\text { tencia } \\
\text { en el } \\
\text { negocio, } \\
\text { que tipo } \\
\text { de pro- } \\
\text { ductos } \\
\text { venden } \\
\text { o produ- } \\
\text { cen? }\end{array}$ & $\begin{array}{l}\text { Al final el cliente es CEA } \\
\text { y no nos fue muy bien } \\
\text { porque hay un inconve- } \\
\text { niente, cuando llega el } \\
\text { pico de la producción } \\
\text { que están en la máxima } \\
\text { producción, entran mu- } \\
\text { chos camiones, entonces } \\
\text { la forma de recibir no } \\
\text { alcanza para que todos } \\
\text { los camiones que llegan } \\
\text { sean recibidos el mismo } \\
\text { día, entonces eso dura } \\
\text { hasta dos o tres días y } \\
\text { eso a nosotros nos perju- } \\
\text { dica porque el señor que } \\
\text { nos transportaba, cobra } \\
\text { más. Entonces salía más } \\
\text { barato venderle al inter- } \\
\text { mediario que venderle a } \\
\text { CEA, que nos sale más } \\
\text { económico que poner } \\
\text { nuestro propio trans- } \\
\text { porte. }\end{array}$ & & & \\
\hline
\end{tabular}

Fuente: Elaboración propia.

En la tabla anterior se hace evidente que Asofruma tiene un solo cliente, CEA, el cual comercializa la fruta y tiene problemas de logística que afecta a los propietarios, especialmente en las temporadas altas de las cosechas. Ellos sostienen que el transporte y los precios para recoger el producto son complicados, dado que se eleva por la falta coordinación y los cuellos de botella que se forman en la entrega. Piensan que la solución sería tener su propio sistema de transporte. Sin embargo, esto también le traería otros 
problemas para garantizar la carga permanente y el mantenimiento de los vehículos. Sería más práctico establecer alianzas con los transportadores para garantizar un precio estable, y con los distribuidores para agilizar los procesos de entrega. Aquí se nota que las preocupaciones son diferentes de los afiliados a Cooagrosur, en donde se refieren a la manera de conseguir y retener los clientes.

\section{Tabla 15}

Estrategias de proyección para la unidad productiva de los asociados a Cooagrosur

\begin{tabular}{|c|c|c|c|c|c|}
\hline & & Fray Luis Pérez & Dorian Niño & $\begin{array}{c}\text { Jesús María } \\
\text { Ariza }\end{array}$ & Yairo Carreño \\
\hline 15 & $\begin{array}{l}\text { ¿Qué } \\
\text { estrategias } \\
\text { utiliza para } \\
\text { mante- } \\
\text { ner a sus } \\
\text { clientes } \\
\text { satisfe- } \\
\text { chos? }\end{array}$ & Calidad. & $\begin{array}{l}\text { Calidad del } \\
\text { producto. }\end{array}$ & Calidad. & Calidad. \\
\hline 16 & $\begin{array}{l}\text { ¿Los clien- } \\
\text { tes llegan } \\
\text { o usted } \\
\text { los busca? } \\
\text { ¿Cómo } \\
\text { busca } \\
\text { nuevos } \\
\text { clientes? }\end{array}$ & $\begin{array}{l}\text { Ganamos } \\
\text { clientes con las } \\
\text { ferias que reali- } \\
\text { zamos. }\end{array}$ & & & \\
\hline 17 & $\begin{array}{l}\text { ¿Qué } \\
\text { cosas } \\
\text { hacen que } \\
\text { su nego- } \\
\text { cio pierda } \\
\text { clientes? }\end{array}$ & $\begin{array}{l}\text { Escasez de } \\
\text { productos. }\end{array}$ & & & \\
\hline
\end{tabular}

Como se puede observar, las respuestas muestran que los afiliados a Cooagrosur se encuentran con problemas diferentes y buscan competir con la calidad del producto, con la participación en ferias. Han visto cómo se pueden perder clientes cuando no se tienen productos para comercializar de manera continua. Es decir, deben 
garantizar el suministro de productos de manera permanente. Su experiencia en participación en proyectos los hace más fuertes en los contactos con entidades como el SENA, y las universidades, y están más al tanto de políticas públicas para el sector agropecuario que les pueda beneficiar.

\section{Control del negocio}

El control del negocio es importante para su continuidad y para verificar los resultados de las operaciones comerciales; esto en las dos organizaciones se tiene en cuenta y cada uno de los entrevistados da su opinión al respecto. En cuadros siguientes se presentan los resultados de las entrevistas realizadas. Mediante esta función administrativa, el propietario de las unidades dispone de información contable que le permita planear y corregir errores, localizar gastos que se desvían de los planes originales y situaciones que debiliten la sostenibilidad y posible crecimiento de la empresa. Es conveniente revisar los instrumentos de control que están empleando, entre los que destacan: un conocimiento sobre costos y control de compras, utilización de insumos, ingresos-egresos en el proceso de producción.

La entrevista no profundizó sobre los análisis financieros del ciclo productivo, estado de resultados, plan o sistema de compra-ventas, porcentajes de depreciación-amortización, y los demás instrumentos, que serán objeto de una entrevista más en detalle y que forman parte de un segundo informe, donde se estará analizando y dando recomendaciones sobre la evaluación económica financiera de estas unidades, y su posibilidad de mantener una producción continua de frutas y hortalizas como insumo de la producción de alimentos saludables. El conocer en detalle y calcular "qué tan bien 
o tan mal" se están desarrollando las acciones, permite corregir errores, comprobar resultados y prever situaciones negativas que, de no llevarse un buen control, no es posible localizarlas y, por lo tanto evitarlas, o al menos reducirlas.

Tabla 16

Control del negocio que realizan los asociados a Asofruma

\begin{tabular}{c|l|l|l|l|l}
\hline 18 & Manuel Donado & Oscar Arraut & $\begin{array}{c}\text { Manuel } \\
\text { Márquez }\end{array}$ & $\begin{array}{c}\text { Gustavo } \\
\text { Camargo }\end{array}$ \\
\hline $\begin{array}{l}\text { ¿asted las } \\
\text { cuentas de } \\
\text { su nego- } \\
\text { cio? Dé un } \\
\text { ejemplo. ¿Es } \\
\text { facil? iEnre- } \\
\text { dado? ¿Qué } \\
\text { se le facilita } \\
\text { yqué se le } \\
\text { dificulta? }\end{array}$ & $\begin{array}{l}\text { Es fácil, a pesar } \\
\text { de que hemos } \\
\text { recibido bastan- } \\
\text { te capacitación } \\
\text { pero seguimos } \\
\text { desorganizados } \\
\text { gemos la plata } \\
\text { la metemos al } \\
\text { bolsillo y de ahí } \\
\text { mismo sale para } \\
\text { todo. }\end{array}$ & $\begin{array}{l}\text { Yo soy el } \\
\text { tesorero } \\
\text { y no llevo } \\
\text { las cuen- } \\
\text { tas regis- } \\
\text { tradas, } \\
\text { solo en } \\
\text { cuaderno. }\end{array}$ & $\begin{array}{l}\text { En libreta llevo } \\
\text { mis cuentas. }\end{array}$ & \\
\hline
\end{tabular}

Fuente: Elaboración propia.

Ellos quieren -y así lo expresan en las entrevistas-, tener un comportamiento del negocio como empresa rentable, por lo tanto resulta posible indicarles que para esto es indispensable comprobar, evaluar, valorar, corregir y evitar gastos innecesarios. Cumpliendo cabalmente con estas funciones se asegura un buen sistema de control de la empresa rural manejada como un agronegocio.

De acuerdo a lo observado, es muy probable que aun cuando los recursos son bastante limitados, ellos los están empleando prioritariamente en actividades dirigidas a penetrar nuevos mercados, sin tener en cuenta costos que buscan fidelizar a clientes y captar a aquellos no atendidos, desarrollar soluciones atractivas que cubran las necesidades de los consumidores. Sin embargo, es un error al no considerar en su real dimensión la importancia que tiene el 
sistema de control, ya que este actúa silenciosamente en la organización y si, el propietario no actúa con prontitud, sus esfuerzos se pueden perder. En la siguiente Tabla se encuentra lo que expresaron los afiliados a Asofruma.

\section{Tabla 17}

Control del negocio que realizan

los asociados a Cooagrosur

\begin{tabular}{|c|c|c|c|c|c|}
\hline & & Fray Luis Pérez & Dorian Niño & $\begin{array}{c}\text { Jesús María } \\
\text { Ariza }\end{array}$ & $\begin{array}{l}\text { Yairo } \\
\text { Carreño }\end{array}$ \\
\hline 19 & $\begin{array}{l}\text { ¿El negocio } \\
\text { deja dinero } \\
\text { para los gas- } \\
\text { tos normales } \\
\text { del mismo? } \\
\text { ¿Y sobra? ¿Es } \\
\text { rentable? }\end{array}$ & Sí. & $\begin{array}{l}\text { Sí alcanza para } \\
\text { los gastos de la } \\
\text { casa y como mi } \\
\text { esposa trabaja } \\
\text { una mano lava } \\
\text { la otra y las dos } \\
\text { lavan la cara. }\end{array}$ & $\begin{array}{l}\text { Alcanza para } \\
\text { todos los gastos. } \\
\text { Queda confor- } \\
\text { me. }\end{array}$ & \\
\hline 20 & $\begin{array}{l}\text { ¿Cómo de- } \\
\text { cide en qué } \\
\text { invertir para } \\
\text { su negocio? }\end{array}$ & $\begin{array}{l}\text { Solo me dedico a } \\
\text { la guayaba. }\end{array}$ & & & \\
\hline
\end{tabular}

Fuente: Elaboración propia.

A la pregunta ¿Cómo lleva usted las cuentas de su negocio? Dé un ejemplo. ¿Es fácil? ¿Enredado? ¿Qué se le facilita y qué se le dificulta? Las respuestas van desde anotar en una libreta, hasta que los domingos saca las cuentas y las anota en una libreta. Consideran que es fácil, por cuanto se limitan a registrar lo que deben pagar y cuándo cobra; separa los gastos y lo que queda son las utilidades. En algunos casos el hijo lleva una relación de gastos en la libreta. Piensan que es fácil después que tengan los recibos a la mano. Para profundizar las respuestas anteriores se les hizo esta pregunta: ¿Que sé le facilita y qué se le dificulta? Ellos consideran que es fácil llevar las cuentas, pero a pesar de haber recibido capacitación son muy desorganizados, y cuando reciben el dinero lo convierten en "contabilidad de bolsillo", de donde toman para todos los gastos. 


\section{Aprendizaje organizacional}

Las organizaciones han cambiado debido a los avances de la información y la nueva visión económica basada en el conocimiento. Por esto, las pequeñas unidades productivas deben realizar un esfuerzo para manejar este nuevo activo, que representa el conocimiento aprendido, y así satisfacer las necesidades del mercado. Una empresa agropecuaria productora alimentos que trata de alcanzar desarrollo, debe tratar que sus directivos adquieran los mejores procesos productivos, esto permitirá obtener productos de calidad, que es lo que busca el cliente; es así que el lograr una producción eficiente del personal, capital y gestión, conlleva a incrementos en la productividad y contribuye al cumplimiento de sus planes y objetivos.

Tabla 18

Aprendizaje organizacional asociados a Asofruma

\begin{tabular}{|c|c|c|c|c|}
\hline & $\begin{array}{l}\text { Manuel } \\
\text { Donado }\end{array}$ & Oscar Arraut & $\begin{array}{c}\text { Manuel } \\
\text { Marquez }\end{array}$ & Gustavo Camargo \\
\hline $\begin{array}{l}\text { ¿De qué } \\
\text { elementos } \\
\text { tecnológicos } \\
\text { dispone para } \\
\text { su negocio? }\end{array}$ & $\begin{array}{l}\text { Computa- } \\
\text { dor. }\end{array}$ & Computador. & No. & $\begin{array}{l}\text { Sí, tengo un sof- } \\
\text { tware para los cer- } \\
\text { dos y computador. }\end{array}$ \\
\hline $\begin{array}{l}\text { ¿Cómo } \\
\text { aprendieron } \\
\text { usted y sus } \\
\text { trabajadores } \\
\text { a realizar las } \\
\text { tareas que } \\
\text { requiere este } \\
\text { negocio? }\end{array}$ & $\begin{array}{l}\text { Capacitacio- } \\
\text { nes que nos } \\
\text { han brinda- } \\
\text { do a todos. }\end{array}$ & Capacitaciones. & $\begin{array}{l}\text { Capacita- } \\
\text { ciones. }\end{array}$ & $\begin{array}{l}\text { Capacitaciones en } \\
\text { emprendimiento, } \\
\text { fianzas, injertación } \\
\text { de mango. }\end{array}$ \\
\hline $\begin{array}{l}\text { ¿Cómo se } \\
\text { toma una } \\
\text { decisión im- } \\
\text { portante para } \\
\text { el negocio? }\end{array}$ & $\begin{array}{l}\text { Se consulta } \\
\text { si no tengo } \\
\text { la capaci- } \\
\text { dad para } \\
\text { resolver un } \\
\text { problema. }\end{array}$ & $\begin{array}{l}\text { Según las al- } \\
\text { ternativas que } \\
\text { tengamos. }\end{array}$ & & $\begin{array}{l}\text { Las mejores deci- } \\
\text { siones se toman } \\
\text { en familia, a veces } \\
\text { las tomo solo. Pero } \\
\text { por lo general en } \\
\text { familia. }\end{array}$ \\
\hline
\end{tabular}

Fuente: Elaboración propia.

Se partió de una tecnología que, en estos momentos, conecta la empresa con el mundo empresarial y con el conocimiento, como es el computador. El propietario plantea que, para convertir la empresa en negocio, tiene un software para la cría de cerdos, y todos tienen 
computador. A través de programas han recibido capacitaciones en emprendimiento, finanzas, injertación de mango. Las decisiones que orientan el curso del negocio se toman de acuerdo al conocimiento adquirido para evaluar las alternativas que tienen, es decir, valoran la información y se apoyan en el buen juicio de la familia.

Tabla 19

Aprendizaje organizacional de los asociados a Cooagrosur

\begin{tabular}{|c|c|c|c|c|c|}
\hline & & $\begin{array}{c}\text { Fray Luis } \\
\text { Pérez }\end{array}$ & Dorian Niño & Jesús Ariza & $\begin{array}{c}\text { Yairo } \\
\text { Carreño }\end{array}$ \\
\hline 22 & $\begin{array}{l}\text { ¿De qué } \\
\text { elementos } \\
\text { tecnológi- } \\
\text { cos dispo- } \\
\text { ne para su } \\
\text { negocio? }\end{array}$ & $\begin{array}{l}\text { Computa- } \\
\text { dor. }\end{array}$ & $\begin{array}{l}\text { Desde el } 2010 \text { para } \\
\text { acá llevaba en un } \\
\text { sistema todas las } \\
\text { actividades que } \\
\text { iba realizando en la } \\
\text { finca, llevaba una } \\
\text { trazabilidad, todo } \\
\text { era sistematizado } \\
\text { pero conté con tan } \\
\text { mala suerte que } \\
\text { el computador me } \\
\text { sacó la pata, eran } \\
\text { dos computadores, } \\
\text { pero la información } \\
\text { la tengo allí. }\end{array}$ & Computador. & \\
\hline 23 & $\begin{array}{l}\text { ¿Cómo } \\
\text { aprendie- } \\
\text { ron usted y } \\
\text { sus traba- } \\
\text { jadores a } \\
\text { realizar las } \\
\text { tareas que } \\
\text { requiere } \\
\text { este nego- } \\
\text { cio? }\end{array}$ & & $\begin{array}{l}\text { Con las capacitacio- } \\
\text { nes y todo lo que } \\
\text { hemos aprendido } \\
\text { me he dado cuenta } \\
\text { de que a uno se le } \\
\text { facilitan las labores. }\end{array}$ & $\begin{array}{l}\text { Todos hace- } \\
\text { mos lo mismo, } \\
\text { nos han dado } \\
\text { las mismas ca- } \\
\text { pacitaciones } \\
\text { y lo hacemos } \\
\text { igual. }\end{array}$ & \\
\hline
\end{tabular}

Fuente: Elaboración propia.

La experiencia les indica que, al no tener procesos claramente definidos, hace que sean menos competitivos y se enfrenten a problemas que afectan su normal crecimiento. Esto en las áreas: administrativa, financiera, producción y comercialización les disminuye su desempeño y productividad. 
En el caso de los asociados a Cooagrosur, el aprendizaje organizacional se hace más notable, ya que al afrontar el desastre producido por la inundación del 2010, se vieron obligados a buscar nuevos conocimientos para la recuperación de sus cultivos, aprender a cultivar especies mejoradas, construir viveros, aplicar técnicas para sembrar, recibir capacitaciones administrativas, etc. En esto, sostiene la mayoría, el computador fue una herramienta esencial; en él era posible darle una trayectoria a la evolución de sus cultivos y registrar esa información. Con las capacitaciones se dan cuenta como el conocimiento aprendido les facilita las labores, y realizan actividades productivas y administrativas basadas en principios que están definidos. Empiezan a confiar más en la tecnología para mejorar sus procesos actuales.

Para ellos, el aprendizaje viene de la fortaleza y como cooperativa, a estar unidos. Miran con optimismo los avances alcanzados... "hemos obtenido algunos beneficios, ahoritica en las procesadoras se darán cuenta la cantidad de herramientas y maquinaria, todo es con proyectos, mientras no se trabaje unidos en la Cooperativa todo se dificulta; es una de las fortalezas que tenemos gracias a la tolerancia que ha habido entre los compañeros y a las ganas que hemos tenido, y algo que nos metió el talante saber hasta dónde éramos capaces, fue la desgracia que nos sucedió". La capacitación para mejorar sus procesos y ahora entender que deben fortalecer la parte administrativa, se puede ver desde su organización cooperativa, entender los procesos, identificar fuerzas impulsoras y restrictivas que influyen en la situación problemática particular.

\section{CONCLUSIONES}

Lo anterior permite afirmar que, el análisis de los procesos organizacionales que siguen los propietarios de las pequeñas unidades 
productivas asociados a Asofruma y la cooperativa Cooagrosur, responde a las particularidades de cada organización y las razones que los llevan a realizarlo, motivados por la elaboración de productos de confitería y fertilizantes para la generación de un nuevo valor agregado a sus cosechas en la zona rural del municipio de Santa Lucía, y las veredas ubicadas en el municipio de Malambo.

Los productos saludables tienen una demanda en crecimiento, por cuanto responden a la necesidad que tienen las personas de evitar la obesidad consumiendo alimentos naturales, aprovechando el sabor y valor nutricional de las frutas. Se trata de un mercado de consumidores que según el estudio realizado por Angie Higuchi (2015) corresponde a familias de ingresos medios y altos, con mayor nivel educativo, y valoran la necesidad de controlar los nutrientes en su alimentación, lo cual le deja un buen margen para su comercialización. Sin embargo, con las tecnologías que se pueden aplicar en su preparación y las innovaciones en la forma de comercialización, y utilizando una publicidad de tipo social, puede llegar hasta grupos de menores ingresos, que también quieren mantenerse sanos, adquiriendo productos alimenticios con nutrientes de tipo natural.

Las frutas, especialmente de las regiones tropicales, tienen un olor, sabor y color que le dan un atractivo adicional para los consumidores, y son fuente de compuestos bioactivos naturales para la industria de alimentos, tal como lo señalan Cárdenas, Arrazola y Villalba (2015), quienes, mediante un estudio, muestran que en los últimos años, ha habido una tendencia global hacia el consumo de alimentos que proporcionen efectos beneficiosos para la salud. La revisión que hacen sobre investigaciones realizadas con anterioridad, 
les indica la importancia en el uso de compuestos bioactivos derivados de plantas como fuente de ingredientes funcionales en los productos alimenticios. Sugieren que pueden disminuir el riesgo de enfermedades cardiovasculares y neurodegenerativas. Las investigaciones citadas se refieren a los componentes que tienen las frutas y aspectos de interés para conservar la salud, como son los componentes antioxidantes.

También se pudo comprobar el papel que cumplen los alimentos para fortalecer el sector agropecuario y los efectos favorables en las familias de bajos ingresos. Producir alimentos a menor costo, y saludables, es otra manera de combatir la pobreza, la cual está asociada a la consecución de alimentos. El mayor indicador de pobreza es la dificultad que tiene la población de bajos ingresos de adquirir alimentos procesados en la ciudad y de tipo natural que llega del campo.

La pobreza se agudiza por las pérdidas y desperdicio de alimentos. Según el estudio de la Organización de las Naciones Unidas para la Alimentación y la Agricultura, FAO (2015), en América Latina es uno de los factores de encarecimiento de los productos alimenticios. Por tal razón, los gobiernos y el sector productivo de los países que forman parte de la Comunidad de Estados Latinoamericanos y Caribeños (CELAC), impulsan políticas públicas para fortalecer el sector agropecuario impulsando la creación de agronegocios que puedan garantizar la seguridad alimentaria de sus respectivos países. También se ha centrado en reducción de Pérdidas y Desperdicios de Alimentos como estrategias de una línea del Plan de Acción para la Seguridad Alimentaria, Nutrición y Erradicación del Hambre 2025. 
Es necesario mirar al agro como espacio básico para la producción de alimentos, tanto en zonas rurales apartadas, como las que se encuentran cerca de los centros urbanos ligadas a la agroindustria. En este caso se observa que estas solo producen alimentos y no aprovechan sus tradiciones culturales, la valoración del patrimonio y la identidad cultural de la región; así, el paisaje, las formas de poblamiento, las costumbres, etc., son intangibles y podían convertirse en una fuente de ingresos, de igual o mayor valor que los mismos alimentos, con preparaciones tradicionales, transformaciones de frutas al natural y el procesamiento artesanal, que le agregan un atractivo especial. En el departamento, los sitios de esparcimiento para la familia y los espacios naturales son una fuente inexplotada de ingresos que, con una publicidad de tipo social, aprovecharían la cercanía a Barranquilla y los centros urbanos cercanos.

Las unidades productivas estudiadas han evolucionado siguiendo una tradición familiar; se trata de personas que se han dedicado a cultivar la tierra desde hace muchos años, pero que por diferentes razones se han retirado hacia otros negocios. El negocio ha evolucionado, de acuerdo a un entrevistado, de la donación de un familiar al cultivo de mango que le propuso Asofruma. Uno de los problemas que afecta es la falta de lluvia. Ellos han tratado de obtener agua mediante pozos subterráneos que les permitan regar los árboles frutales y garantizar las cosechas.

Importante para los asociados a Asofruma es practicar ciertos valores como la perseverancia, porque les produce satisfacción cuando logran vencer los tropiezos y conseguir lo que se han propuesto. Un principio de la asociación que se reconoce es la solidaridad, porque allá como no se tiene para producir, se comparte el 
trabajo, de manera que los productos se intercambian, "... ellos me dan yuca, y con eso ayudo un poco a la gente en su modo de vivir, tengo una persona que es la encargada de la finca que trabaja también para su propio negocio de cría".

Cooagrosur tiene mayor experiencia en la planeación de actividades que deben orientar el negocio de la producción de frutas y hortalizas. En las entrevistas se pone de manifiesto la manera como planifican el día a día de este negocio. Para uno cada día se puede planear un día antes. Para otros es necesario revisar las necesidades prioritarias que presenta el cultivo; se trata de retirar la maleza y asegurarse de que el cultivo no tenga plaga. Es un proceso que se inicia cuando se examina el cultivo y se empieza a decidir qué debe atenderse primero, por lo general se trata de las plagas, por cuanto estas afectan directamente a las plantas, pero la maleza también requiere ser eliminada para obtener una planta sana. "Un día antes yo digo: mañana voy para el monte y me pongo en esto y eso, ya yo llevo en el perfil qué es lo que voy a hacer, no voy a esperar llegar para entonces quedarme mirando para ver por dónde voy a empezar. No, yo llego y enseguida arranco porque ya eso viene del día antes o en la noche. Y si yo llego y hay otra labor primordial, cambio el chip".

El control del negocio es importante para su continuidad y para verificar los resultados de las operaciones comerciales; esto en las dos organizaciones se tiene en cuenta y cada uno de los entrevistados da su opinión al respecto. Aun cuando saben de la importancia de esta función administrativa, los propietarios de las unidades no disponen de información contable que les permita planear y corregir errores, localizar gastos que se desvían de los planes originales 
y situaciones que debiliten la sostenibilidad y posible crecimiento de la empresa. Es necesario revisar los instrumentos de control que están empleando, entre los que destacan: un conocimiento sobre costos y control de compras, utilización de insumos, ingresos-egresos en el proceso de producción.

Las organizaciones han cambiado debido a los avances de la información y la nueva visión económica basada en el conocimiento. Por esto, las pequeñas unidades productivas realizan esfuerzos para manejar el nuevo activo que representa el conocimiento aprendido y así satisfacer las necesidades del mercado. Se obtiene una empresa agropecuaria, productora de alimentos en mejores condiciones de producción, si logran que sus directivos adquieran los mejores procesos; esto permitirá ofrecer productos de calidad, que es lo que busca el cliente. Tales resultados se logran con una producción eficiente del personal, capital y gestión, lo que conlleva a incrementar la productividad y contribuye al cumplimiento de sus planes y objetivos.

Los propietarios conciben el aprendizaje como resultado de estar asociados. Miran con optimismo los avances alcanzados, con las organizaciones como Asofruma y Coagrosur, que representan su fortaleza. Resaltan los logros obtenidos por Cooagrosur: la procesadora de alimentos que fue producto de un proyecto impulsado por esta organización, con la que han adquirido herramientas y maquinaria. El haber superado la inundación es un hito que les proporciona fuerzas para abordar nuevos proyectos. Consideran que mientras no se trabaje unidos todo se dificulta. Saben que el conocimiento que les proporcionan las capacitaciones que ofrecen los proyectos es esencial para mejorar sus procesos, y ahora entienden 
que deben fortalecer la parte administrativa, no solo para sus organizaciones, sino que es necesario ver los procesos como parte de sus propias unidades productivas, identificar fuerzas impulsoras y restrictivas que influyen en la situación problemática particular, para pasar de la situación actual a otra mejorada en un tiempo determinado.

\section{REFERENCIAS BIBLIOGRÁFICAS.}

Alimentec (2016). Informe de Resultados Producto del Desarrollo Alternativo: Semillas para la Paz. IX Feria Alimentec 2016.

Arguedas-Gamboa, P., Mora-Molina, J. y Sanabria-Mora, J. (2015). Comparación del contenido de carotinoides en productos nutracéuticos elaborados a partir de dos variedades de camote y yuca. Tecnología en Marcha, 28(4), Octubre-Diciembre, 42-53.

Asociación Nacional de Industriales ANDI (2015). Balance 2015 y Perspectivas 2016. Bogotá, Colombia: ANDI.

Barrena, R., García, T. y López-Mosquera, N. (2016). Determinantes socioeconómicos y emocionales en el consumo de nuevos alimentos. Un estudio piloto. En ITEA, 112(1), 88-103.

Cárdenas, Arrazola y Villalba M. (2015). Frutas tropicales: fuente de compuestos bioactivos naturales en la industria de alimentos. Ingenium, 17(33), 29-40.

Castañeda, J., Ruiz, A., Guardiola, O. y Estrada-López, H. (2010). Validación de la nasa hondureña para el fortalecimiento de la pesca artesanal. Barranquilla, Colombia: Económicas CUC, 29(29), 125.

Cerdeño, V. (2014). Treinta claves del mercado alimentario. Revista Distribución y Consumo, (1), 5-28.

Colciencias (2005). Bases para la formulación del Programa Nacional de 2005-2015. Bogotá: Colciencias. 
Comisión Económica para América Latina y el Caribe (CEPAL) (2015). Perspectivas de la agricultura y del desarrollo rural en las Américas: Una mirada hacia América Latina y el Caribe 20152016. San José de Costa Rica: CEPAL-IICA.

Congreso Centroamericano del Sector Lácteo la Cámara Nacional de Productores de Leche (2012). Memoria Congreso Nacional Lechero 2012. San José de Costa Rica Cámara Nacional de Productores de Leche.

Denzin, K. (2001). The reflexive interview and a performative social science". Qualitative Research, 1(1), 23-46, SAGE Pub.

Estrada-López, H. y Jiménez, M. (2012). Caracterización de Unidades productivas de lacteos en el municipio de Sabanalarga, corregimientos de Isabel López, Cascajal y Gallegos, departamento del Atlántico. Desarrollo Gerencial, 4(1). Recuperado de: http://publicaciones.unisimonbolivar.edu.co/rdigital/ojs/index. php/desarrollogerencial/article/view/1153

Estrada-López, H. (2008). Plan Estratégico para la empresa Decorhouse 2007-2009 bajo metodología MMGO. Desarrollo Gerencial, 4(1). Recuperado de: http://publicaciones.unisimonbolivar.edu.co/rdigital/ojs/index.php/desarrollogerencial/article/ view/1148

Estrada-López, H., Iglesias-Navas, M., Saumett-España, H., Osorio-Torres, C., Rosero-Flórez, K., Uribe-Urán, A., Sánchez, M. (2015). Gestión de Marketing para el Sector Agroindustrial. Barranquilla, Colombia: Editorial Universidad Simón Bolívar.

Estrada-López, H., Martínez, J. y Ruiz, A. (2013). Gestión de procesos para el cultivo de bocachico en Jagüeyes con la técnica estandarizada de fertilización orgánica al $2 \%$ en el municipio de Piojó, departamento del Atlántico. Barranquilla, Colombia: Editorial Universidad Simón Bolívar. 
Estrada-López, H., Saumett-España, H y Montenegro, A. (2017). Direccionamiento Estratégico y Aprendizaje. Barranquilla, Colombia: Editorial Mejoras.

Estrada-López, H., Saumett-España, H y Sánchez, M. (2015). Estrategias de desarrollo en pequeñas empresas del departamento del Atlántico. Barranquilla, Colombia: Editorial Educosta.

Estrada-López, H., Saumett-España, H., Rivera, R., Rosero-Flórez, K., Acosta, N., Martínez, J. y Villanueva, A. (2013). Cultivo de bocachico en Jagüeyes con alimentación natural: "Estrategia empresarial para el sector agropecuario". Barranquilla, Colombia: Editorial Universidad Simón Bolívar.

FAO Organización de las Naciones Unidas para la Alimentación y la Agricultura (2014). Perspectivas Agrícolas 2013-2023. París, FR.

FAO Organización de las Naciones Unidas para la Alimentación y la Agricultura (2015). Reducción de Pérdidas y Desperdicios de Alimentos, una línea de acción del Plan para la Seguridad Alimentaria, Nutrición y Erradicación del Hambre de la CELAC 2025. Santiago de Chile: FAO.

Fuentes-Berrío, D., Acevedo-Correa, V. y Gelvez-Ordoñez, M. (2015). Alimentos Funcionales: Impacto y Retos para el Desarrollo y Bienestar de la Sociedad Colombiana. Biotecnología en el sector agropecuario y agroindustrial, 2(13), 140-149.

Fundación Chile (2013). Chile saludable. Oportunidades y desafios de innovación, (2). Recuperado de: http://fch.cl/wp-content/ uploads/2015/01/estudio-chile-saludable-volumen-11.pdf

Hidalgo, N. (2009). El Sector de la industria alimenticia de Costa Rica: una perspectiva desde la cadena de valor. San José de Costa Rica: Universidad de Costa Rica.

Higuchi, A. (2015). Características de los consumidores de productos orgánicos y expansión de su oferta en Lima. Apuntes XLII, 
(77), segundo semestre 2015, 57-89.

Iglesias, A. (2014). Merchandising: evolución reciente y tendencias futuras en el sector del gran consumo. Tesis. Madrid: Universidad de ICADES.

Koontz, H., Weihrich, H. y Cannice, M. (2012). Administración. Una perspectiva global y empresarial. 14 a ed. México: McGraw-Hill. Lee, Y. y Chang, H. (2008). "Relations between team work and innovation in organizations and the job satisfaction of employees: a factor analytic study". International Journal of Management, 25(3), 732-739.

Marais, H. (2012). A Multi-Methodological Framework for the Design and Evaluation of Complex Research Projects and Reports in Business and Management Studies. Electronic Journal of Business Research Methods, 10(2).

Méndez, C. (1995). Metodología: Guía para la elaboración de Diseños de investigación en Economía, Administración y Ciencias Contables. $2^{a}$ ed. Bogotá: Editorial McGraw-Hill.

Morales, F. (2015). Mercados Emergentes: Qué mercados deberíamos potenciar de acuerdo al nuevo escenario mundial. Lima: Congreso Latinoamericano de Economía.

Mosquera, V. y Muñoz, F. (2016). Validación del nivel de aceptación de comida rápida saludable en ejecutivos de la ciudad de Bogotá mediante la aplicación del modelo de Teoría de Comportamiento Planificado. Tesis Colegio de Estudio Superiores de Administración. Bogotá: Maestría en Dirección de Marketing.

Organización Panamericana de la Salud (2014). Estadísticas sanitarias mundiales 2014. Ginebra 27, Suiza: Publicaciones de la Organización Mundial de la Salud.

Padilla, M. (2013). Evaluación del potencial nutritivo y nutracéutico de galletas elaboradas con berro deshidratado como coloran- 
te y saborizante. Riobamba, Ecuador: Tesis Universidad Escuela Superior Politécnica De Chimborazo.

Plan Nacional de Desarrollo-PND (2015 - 2018). Todo por un nuevo país. Recuperado en: http://wp.presidencia.gov.co/sitios/especiales/Documents/20150616-especial-plan-nacional-desarrollo/ index.html\#conten

Reales, R., Estrada-López, H. (2012). La toma de decisiones en las pequeñas organizaciones del sector cooperativo y estilos de dirección. Revista Desarrollo gerencial, Barranquilla.

Tamayo (2008). Metodología formal de la investigación científica. Bogotá: Limusa.

Torrija, E. (2016). Alimentos funcionales y obesidad. Interés y realidad. Real Acad Farm, 82, 260-276.

Universidad Nacional Autónoma de México UNAM. Torres Salcido y Morales Ibarra (coordinadores) (2014). El agro y las áreas rurales en el México del siglo XXI. México: Editorial Siglo XXI.

Weber (1986). Social Research. International Quarterly, 53(1), $125-132$.

\section{Cómo citar en este capítulo}

Saumett-España, H. G., Estrada-López, H. H., \& Cáceres-Martelo, A. M. (2017). Estrategias de administración de las pequeñas unidades productivas del estudio. En H. H. Estrada-López H. G. Saumett-España, M. A. Iglesias-Navas, M. J. Bahamón, A. M. Cáceres-Martelo, C. E. Restrepo Flórez, . . A. Díaz Pérez, Productos de confitería nutracéutica. Una opción empresarial para cultivadores de frutas y hortalizas (pp.79-140). Barranquilla: Universidad Simón Bolívar. 